\title{
ORIGEN Y DESARROLLO POSITIVO DE LA LEXICOGRAFÍA BILINGÜE ESPAÑOL-ITALIANO (SIGLOS XVI-XIX)
}

\author{
José Joaquín Martínez Egido
}

Universidad de Alicante

RESUMEN

La lexicografia bilingüe español-italiano tiene su origen a finales del siglo XV con el nacimiento de las lenguas vernáculas como vehículos eficientes de comunicación entre los pueblos. En primer lugar será en obras de pequeña extensión y de configuración semántica, las nomenclaturas, para dar lugar a obras más extensas e importantes, los diccionarios. Este trabajo muestra el origen y el desarrollo de esta lexicografia bilingüe desde esos inicios hasta el final del siglo XIX. La exposición se realiza dividiendo la producción lexicográfica en cuatro momentos temporales, resultantes del desarrollo e importancia de las obras, tanto por su extensión como por la técnica lexicográfica que se utiliza. Por todo ello, como resultado final, se asiste a todo el devenir de esta práctica lexicográfica en la que se observa cómo logra alcanzar un estadio positivo comparable al de otras lexicografias bilingües del español.

Palabras clave: Lexicografia; bilingüe; español-italiano; historia. ABSTRACT

Spanish-Italian bilingual lexicography originated in the late 15th century with the birth of vernacular languages as efficient means of communication between people. Firstly, short, semantic nomenclatures were created, followed by dictionaries as more extensive and important works. This article shows the origin and development of Spanish-Italian bilingual lexicography, from these early beginnings up to the end of the 19 th century. For the purposes of this study, lexicographical production is divided into four time periods, based on the development and importance of the works, both in terms of length and the lexicographical technique used. Thus, the complete evolution of this lexicographical practice is presented, reflecting how it managed to achieve a positive juncture comparable to that of other Spanish bilingual lexicography.

Keywords: Lexicography; bilingual; Spanish-Italian; history. 


\section{INTRODUCCIÓN}

La elaboración de diccionarios en el siglo XXI es el resultado de una larga tradición y de una ardua planificación teórica y práctica (Azorín Fernández 2003: 31-52) que comenzó con el nacimiento de las lenguas vernáculas. El desarrollo de éstas y la necesidad de su aprendizaje por extranjeros ayudaron a que la lexicografía se desarrollara como disciplina lingüística. Podemos decir que de la necesidad del aprendizaje de lenguas extranjeras surge el producto lexicográfico.

La lexicografía bilingüe del español y del italiano participa de esa tarea conjunta de los diferentes profesores y lexicógrafos que han ido trabajando a lo largo de los siglos con la finalidad de elaborar productos eficaces para sus propósitos docentes. Estos productos no debían ser exclusivamente diccionarios extensos, como los que conocemos en nuestros días, sino que podrían tratarse de pequeños vocabularios u otros tipos de agrupaciones de léxico destinados a ser memorizados con miras a la adquisición de un vocabulario básico.

En este trabajo, bajo la directriz que nos proporciona el eje cronológico, se muestra cuál ha sido la trayectoria de la lexicografía hispano-italiana desde sus orígenes hasta finales del siglo XIX. Llega a ese momento con la adquisición plena de una técnica lexicográfica ya depurada, basada en unos principios teóricos suficientes que la harán entrar en el siglo XX preparada para dar lugar a obras cada vez más adaptadas a los principios de la técnica lexicográfica moderna y a las necesidades de los usuarios.

En el eje cronológico, para el desarrollo de este trabajo, se han distinguido cuatro apartados, el primero para explicar los orígenes (siglos XV y XVI) y los tres restantes para constatar el desarrollo de la producción lexicográfica bilingüe español-italiano (siglos XVII, XVIII y XIX). En cada uno de ellos se ha diferenciado lo que fue la actividad lexicográfica general de lo que resultó de la actividad lexicográfica particular de la lexicografía bilingüe español-italiano. Dentro de ésta se ha prestado atención tanto a la producción bilingüe menor, las pequeñas obras o diferentes productos lexicográficos que contribuyeron tanto a la enseñanza del español como del italiano en tanto que lenguas extranjeras, como a la considerada mayor, la realización de diccionarios extensos en los que existió una voluntad manifiesta de recoger el mayor número de voces de una lengua.

\section{LA LEXICOGRAFÍA BILINGÜE ESPAÑOL-ITALIANO: SIGLOS XV Y XVI}

\subsection{Actividad lexicográfica}

El siglo XV marca el comienzo de la tradición lexicográfica entre el español y el italiano como lenguas de trabajo en productos lexicográficos pues es, precisamente, en este momento cuando las lenguas vernáculas se afianzan como lenguas de comunicación y de cultura y, por ello, serán necesarios diversos materiales que apoyen su aprendizaje, tales como gramáticas, vocabularios y diccionarios. Durante toda la Edad Media (Von Gemmingen 2003: 151-174), la práctica lexicográfica se insertó dentro de la consideración del léxico como parte del estudio gramatical siempre del latín y en latín, por lo que los estudios sobre el léxico deben rastrearse en obras diversas con características bien 
diferenciadas en su contenido y en su forma, como fueron las gramáticas propiamente dichas, las obras etimológicas, las Summas, los pseudoccionarios, las listas de palabras en los Nominalia y los apéndices de los Colloquia y, por último, los glosarios (Martínez Egido 2006: 2-6).

La tradición lexicográfica del español tiene su primer representante sustancial en 1490 con la publicación en Sevilla del Universal Vocabulario en latín y en romance de Alfonso Fernández de Palencia (Alemany 1981, Medina Guerra 1991), concebido como un instrumento útil para el aprendizaje del latín y destinado a los estudiantes y a los clérigos. $\mathrm{Su}$ autor intentó desligarse de la tradición de los glosarios medievales que venían utilizándose, muchos de ellos desde el siglo VIII, y que acumulaban multitud de errores, por lo que ofrecían un latín viciado. Así, Fernández de Palencia, asumiendo los presupuestos pedagógicos humanistas de volver a los textos originales clásicos para su estudio y posterior enseñanza (Martínez Egido 2008: 229-232), construyó y redactó su vocabulario, el cual, a pesar de ser un diccionario monolingüe latino, tiene la particularidad de presentar la traducción en español de todo lo aportado en latín y, sobre todo y más importante, es que es el primer intento de formalizar un diccionario general de la lengua sin una limitación en su extensión ${ }^{1}$.

Casi de forma inmediata continúa la tradición con los dos diccionarios de Antonio de Nebrija (Alvar Ezquerra 1992, 1988; Perona 1994; Guerrero 1995) Dictionarium ex Sermone Latino y Dictionarium ex hispaniensi in latinum sermonen o Vocabulario español-latin ${ }^{2}$, publicados en 1492 y en 1495, respectivamente. Con ellos comenzará verdaderamente la andadura lexicográfica del español pues, aunque coetáneo de Alfonso de Palencia y movidos ambos por vencer la barbarie en la que se encuentra el estudio del latín en la Península, supo deslindarse completamente de la tradición medieval y encauzar la práctica lexicográfica hacia lo estrictamente lingüístico y, además, sentar las bases de todo lo que será la labor lexicográfica del español durante los siglos siguientes.

Junto a la aparición de estos tres diccionarios, por toda Europa también se publican lo que se conoce con el nombre de Nomenclaturas que son "repertorios léxicos en más de una lengua que ordenan sus materiales de acuerdo con el contenido o con la cosa designada y no con la forma de los términos consignados" (Ayala Castro 1992: 437) y que van a responder a la necesidad práctica del aprendizaje de las lenguas modernas europeas de la Europa de los siglos XVI y XVII. Así, en Venecia en 1477 y de autor anónimo aparecerá una nomenclatura con el italiano y el alemán, Introito e porta de quele che voleno imparare e comprender todescho a latino, cioe italiano (Lope Blanch 1990: 113), la cual, posteriormente, se verá incrementada con otras lenguas como la latina y la francesa en la edición de Roma de 1510. Y será en la edición de Francisco Garonum de 1526 cuando el español se añada a las lenguas contempladas en ella. Ésta parece ser la fecha del inicio de la andadura lexicográfica conjunta del español y del italiano.

\footnotetext{
${ }^{1}$ La consulta de este diccionario puede realizarse en la edición publicada en la Biblioteca Virtual Cervantes: http://wwww.cervantesvirtual.com/FichaAutor.html?Ref $=148$

${ }^{2}$ La consulta de este diccionario puede realizarse en la edición publicada en la Biblioteca Virtual Cervantes: http://www.cervantesvirtual.com/servlet/SirveObras/07032774389636239647857/index.htm
} 
De esta forma, el siglo XV se configura como el anticipo de las bases teóricas y prácticas de lo que será posteriormente la práctica lexicografía bilingüe en general, y en particular la de español e italiano, pues, aunque no hay ningún producto lexicográfico conjunto de las dos lenguas, los diccionarios extensos, por un lado, seguirán el modelo de diccionario que configura Nebrija, tanto por la relación de los elementos que integran su macroestructura como por la forma escueta y estrictamente lingüística de resolver su microestructura. Por otro lado, la creación de múltiples nomenclaturas y vocabularios breves en las que se incluya al español y al italiano serán, como se demuestra por la cantidad tanto de obras como de ediciones existentes en el mercado, el material preferido y utilizado mayoritariamente para el aprendizaje de las dos lenguas.

Por lo que respecta al siglo XVI, se constata una total ausencia de diccionarios de lengua monolingües del español que contrasta con la ingente actividad lexicográfica bilingüe y plurilingüe que se desarrolla durante esta centuria (Carriazo y Mancho 2003: 205-234). La causa de este doble hecho es fundamentalmente práctica y se debe a la necesidad que muestra la sociedad europea de aprender las lenguas modernas y, en especial, el español (Martínez Egido 2006: 1-3). Se aúnan en este proceso dos características que van a permanecer unidas hasta nuestros días como son la consideración del diccionario como producto pedagógico y también como producto comercial sujeto a la demanda del público comprador. De esta forma, el español aparece como lengua integrante de diversos materiales lexicográficos, pues junto con los diccionarios de gran extensión como los bilingües de español con el árabe (Alcalá $1505^{3}$ ), con el francés (Ledel $1565^{4}$, Hornkens $1599^{5}$ ), con el inglés (Percyvall $1591^{6}$, Minsheu $1599^{7}$ ) y con el italiano (Las Casas $1570^{8}$ ), aparecerán también y de forma muy numerosa los pequeños vocabularios (Nieto 1999) insertos en diferentes tipos de obras que responden a las características básicas de las nomenclaturas ${ }^{9}$.

\subsection{La producción lexicográfica bilingüe español-italiano}

La producción lexicográfica conjunta del español y del italiano a lo largo del siglo XVI sigue los pasos de otras producciones lexicográficas del español con otras lenguas del

\footnotetext{
${ }^{3}$ Vocabulista arabigo en letra castellana, Granada.

${ }^{4}$ Vocabulario de los vocablos que más comunmente se suelen usar, Alcalá.

${ }^{5}$ Recueil de Dictionaires François, Espagnols et latins. Recopilación de Diccionarios Franceses, Españoles y Latinos. Congesta Diccionariorum, Gallicorum, Hispanicorum et Latinorum, Bruselas, R. Velpius.

${ }^{6}$ Bibliotheca Hispanica, containig a grammar, with a dictionarie in Sapanisch, English and Latine, gathered out of divers good authors: very profitable for the studious or the Spanish toong, by R. Percyvall, Gent., the dictionarie being enlarged with the latine by the advice and conference or Master Thomas Doyley, Doctor in Phisiche, Londres.

${ }^{7} \mathrm{~A}$ dictionarie in spanish and english, Londres.

${ }^{8}$ Vocabulario de dos lenguas toscana y castellana, Sevilla.

${ }^{9}$ Presentan un léxico distribuido por campos nocionales, se redactan en más de una lengua, no son obras independientes, tienen un carácter didáctico, solo recogen el vocabulario usual de una lengua, se constatan sobre todo los sustantivos y no suelen ofrecer la definición de los vocablos que recogen (Ayala Castro 1992: 439).
} 
occidente europeo. Así, junto a la aparición de un diccionario bilingüe extenso, como fue el de Las Casas, existieron numerosos materiales lexicográficos de corta extensión que seguían la estela ya iniciada en la centuria anterior como se ha constatado.

En esta última línea, a la nomenclatura publicada por Garonum en 1526, a la que anteriormente se hacía referencia, le siguen otras muchas que inician a su vez su propia descendencia (Acero 2003: 175-182). En todas ellas el español y el italiano aparecen como integrantes de las equivalencias ofrecidas. Entre las más fructíferas cabe destacar la iniciada por Nöel Berlaimont con su Vocabulaire pour apprendre legiérament à bien lire, escripre, parler François et Flameng, lequel est mis tout le plus part par personnaiges (Bourland 1933) publicado en 1530, aunque la primera edición constatada es de 1536. Su finalidad era doble, servir tanto para el aprendizaje del francés y del flamenco como para ser utilizado como manual de enseñanza religiosa. Por eso su contenido es tan heterogéneo: un glosario de palabras corrientes, los días de la semana, una lista de los numerales, un conjunto de oraciones como el Padrenuestro, el Avemaría, los Artículos de la fe, un tratado de pronunciación francesa y tres diálogos (Martín Gamero 1961: 58-59, Caravolas 1995: 293). $\mathrm{Su}$ éxito fue rotundo con numerosísimas ediciones que se prolongarán hasta bien entrado el siglo XVII, hasta el punto de que pasa de sus 84 páginas iniciales hasta las 448 de la edición de 1583. Será en su edición de 1558 cuando se integren en él por primera vez el español y el italiano junto con el neerlandés y el francés, originarios de la primera edición. En este mismo ámbito debemos reseñar la obra de Ambrosio Calepino publicada en 1502, Diccionarium, que en su primera edición sólo incluía unas voces latinas traducidas al griego pero a las que, posteriormente, se le fueron añadiendo nuevas lenguas, el italiano en 1550 y el español en $1558^{10}$, por lo que a partir de esta fecha estas dos lenguas también aparecen unidas en un producto lexicográfico de estas características. En estas mismas fechas, en Lovaina, en 1551, se publica la obra anónima Vocabulario de quatro lenguas. Tudesco, francés, latino y español, muy provechoso para los que quisieren aprender estas lenguas $^{11}$. Como se observa en su título, la característica básica de este tipo de obras es su carácter práctico en el contexto cultural que exige la expansión de las lenguas vernáculas. El contenido de este libro es similar en todas sus versiones: un glosario de palabras usuales; los números y los días de la semana; diálogos; cartas y documentos comerciales que sirvan como modelos; oraciones cristianas; un pequeño tratado de pronunciación (Sánchez Pérez 1992: 19-20). La funcionalidad y el éxito de esta obra se comprueba cuando se constata que de las 84 páginas que tenía la primera edición se pasa a las 448 en la edición de 1583, fecha en la que ya no se introdujo ninguna modificación sustancial del texto (Martín Gamero 1962: 61-64).

\footnotetext{
${ }^{10}$ A. Calepino, Dictionarium Quator Linguarum, Gallicae, Latinae, Italicae, Hispanicae... Lovaina, B. de Gravio, 1558. En la Biblioteca Nacional de Madrid se encuentra una edición de 1618 en la que ya se incluyen siete lenguas: F. Ambrosii Calepini ... ord. Erem. S. Agustini Dictionarium septem linguarum, hebraicae, graecae, latinae, italicae, germanicae, hispanicae, et gallicae. 3/20325.

${ }^{11}$ Esta edición hecha en Lovaina por el impresor Bartolomé Gravio tuvo muchas reimpresiones, en 1556, 1558, 1560. En 1569 se sustituyó el latín por el italiano, y en 1576 se añadió el inglés y el alemán. Esta obra ya con seis lenguas continuó publicándose durante todo el s. XVI y s. XVII.
} 
Se debe constatar también, dentro de las aportaciones lexicográficas que se reseñan en este trabajo, que unos años antes, en 1543, se publicó en Venecia la obra de Francesco Alunno, Le richezze della linga volgare, con un apéndice en el que se recogen las equivalencias entre diversas lenguas llamada Voci o vero vocaboli, che vsano $i$ Latini, Greci, Provenzali, Francesi, Sapgnuoli, Thedeschi, Englesi, Gothi, et altre nazioni (Alvar Ezquerra 1994). El vocabulario que contiene el italiano y el español contaría con unos 1400 vocablos (Gallina 1959: 45).

En 1567 se publicó otra obra que gozaría de un gran número de ediciones como fue el Nomenclator, omnium rerum propria nomia variis linguis explicata indicans de Adrianus Junio en Amberes. Tiene como lengua de entrada el latín, a la que le siguen las equivalencias en siete lenguas: griego, alemán, flamenco, francés, italiano, español e inglés. Presenta la particularidad de que ofrece las definiciones de los vocablos incluidos (Gallina 1959: 133-147). En esta misma línea también cabe reseñar la compilación de glosarios de español e italiano con la intención de facilitar la lectura de obras literarias, como fueron los redactados por Alfonso de Ulloa para La Celestina ${ }^{12}$ o para Orlando Furioso ${ }^{13}$. Son listados de palabras utilizadas en cada una de las dos obras traducidas al italiano.

Junto a este tipo de obras descritas, en el siglo XVI aparecen por primera vez diccionarios extensos bilingües de español e italiano que van configurando una línea de trabajo lexicográfico que se perpetuará en el tiempo. Así en 1520, en Venecia, Cristóbal Escobar traduce al italiano el diccionario de Nebrija, Vocabularium ex latino sermone in siciliensem et hispaniensem denuo traductum. Este hecho subraya y anticipa la importancia de la obra de Nebrija para la lexicografía posterior bilingüe española-italiana, pues el Vocabulario del maestro lebrijano se convertirá en el patrón fundamental y guía de todos los lexicógrafos de esta centuria y también de la siguiente.

No obstante, el primer diccionario bilingüe español-italiano concebido como tal fue el escrito, que no publicado porque nunca vio la luz, en 1562 por Nicolás Landucci, Dictionarium Lingue Toscanel A Nicholao Landuchio ciuital tis Luce regionis Tofcane fuel vernacule lingua peritiffimo/Vocabulario Español, Italiano/ Frances y Vyzcaino. Anno. I.D.LXII ${ }^{14}$. Es un manuscrito encuadernado de sólo $8 \mathrm{~cm}$ de largo por $22,5 \mathrm{~cm}$ de alto. La obra se compone de 328 hojas numeradas, lo que supondría un total de 656 páginas. Se encuentra dividido en tres partes independientes: español-italiano, español-francés y español-vasco. La parte español-italiano consta de 113 hojas de las que las últimas 7 están en blanco, por lo que una vez restadas éstas y la portada, el diccionario se compone de 105

\footnotetext{
${ }^{12}$ Introduzione del signor Alphonso di Uglioa, nella quale s'insegna pronunicare la lingua spagnuola, con una expositione da lui fatta nella Italiana, di parecchi vocabloi Hispagnuoli difficili, contenuti quasi tutti nella Tragicomedia di Calisto e Melibea o Celestina, Vinegia, appresso Gabriel Giolito e fratelli, 1553.

${ }^{13}$ Exposición de todos los lugares comunes difficultosos que en el presente libro se hallan. Con una breve demostración de muchas comparaciones y sentencias que el Ariosto ha imitado en diversos Auctores contenidas en el. Recogidas por el S. Ludovico Dulce, y nuevamente copiladas y traduzidas del Thoscano idioma en Romance Castellano por el S. Alonso Ulloa, con una exposición por el hecha, de algunos vocablos Castellanos en lengua Thoscana, Leon, en casa de Mathias Bonhome, 1556.

${ }^{14}$ En este trabajo se maneja el manuscrito 8431 de la Biblioteca Nacional, Madrid.
} 
hojas escritas por las dos caras y una sólo por una. Así, según el cálculo estimado ${ }^{15}$, recogería 8.440 entradas de las que solamente ofrece la traducción al italiano sin ningún tipo de información adicional. Por este motivo se encontraría a medio camino entre la tradición formulada por las nomenclaturas y los diccionarios verdaderamente extensos. Cabe señalar que la ausencia de cualquier tipo de información, salvo la traducción directa de la entrada, sigue la estela de la confección de la microesctructra realizada por Nebrija. Por todo ello, y sobre todo por su carácter de obra inédita, queda como testimonio de una labor lexicográfica realizada pero no utilizada por el público ni tampoco influyente en la lexicografía posterior.

Será casi una década más tarde, en 1570 , cuando aparezca la gran obra lexicográfica bilingüe español-italiano de la centuria, el Vocabvlario de Cristóbal de Las Casas. En su portada se lee:

VOCABVLARIO / DE LAS DOS LENGVUAS TOSCA / NA Y CASTELLANA DE CHRIS / TOVAL DE LAS CASAS. / EN QUE SE CONTIENE LA DECLARA / cion de Tolcano en Caltellano, y de Caltellano / en Tolcano. En dos partes / CON VNA INTRODVCION PARA LEER, / y pronunciar bien entrambas lenguas. / DIRIGIDO AL

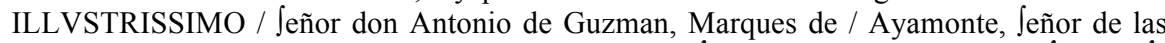
villa de / Lepe y la Redondela. / Con Priuilegio de Caltilla y de Aragon. / Vende Je en cala de Francifco de Aguilar mercader de libros. / EN SEVILLA. / 1570.

El diccionario va precedido de veintidós páginas sin numerar en las que se incluye un material diverso pero característico de las obras de este período. En las primeras cuatro páginas aparecen las aprobaciones en las que se reconoce el ingente trabajo realizado por el autor, la novedad que supone su obra y lo útil que va a ser para sus posibles destinatarios:

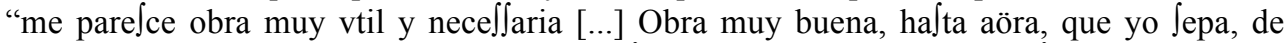
nadie intentada; $[. .$.$] Vocabulario muy copio \int_{0}[\ldots]$ en el qual auiades pue to mucho trabajo y ocupación”. A continuación, en las cinco páginas siguientes, el autor a modo de prólogo, en su carta al Marqués de Ayamonte, justifica la necesidad de esta obra apelando a la demanda existente en el aprendizaje de lenguas extranjeras en general y, más concretamente, en el caso de las lenguas italiana y española. Junto a esa necesidad también subraya la riqueza que supone su conocimiento:

[...] los hombres bien aficionados, y amigos de Jaber, han pretendido el conofcimiento de las lenguas eftrangeras, para gozar de la riqueza de'llas, y trafladarla à nue $\int$ tra nacion. Entre las quales, vna de las que mayor teforo tiene, y mejor comodidad para alcançarla, es la To $\int$ cana. Cuyo cono cimiento ha procura, y procura tanta gente, que ya no ay hombre que no pretenda, ò de $\iint e$ alomenos aprendera: y cierto con muy gran razon. Porque de mas dela necefidad que ay, por el contino trato con la gente Italiana, ha auido Jiempre, y ay tanta curiofidad, y diligencia en adornar, y ennoble $\int e r$ Ju tierra de todo genero de buenas letras; $[\ldots]$.

Estas dos razones enunciadas por Las Casas son las que, sin lugar a dudas, hacen aflorar la producción ingente de obras lexicográficas, aunque, la primera de ellas es la que,

\footnotetext{
${ }^{15}$ El cálculo del número de entrada se ha realizado según el promedio de 40 entradas por hoja, pues el número de cada una de ellas oscila entre las 37 y las 43 entradas por hoja.
} 
evidentemente, tuvo un mayor peso específico, pues ya se ha apuntado que la vertiente comercial, emanada de la necesidad de los usuarios, casi siempre es la que moverá la producción lexicográfica. Para terminar este preámbulo, el autor también ofrece, en las siete páginas siguientes, una serie de poemas según el gusto y la costumbre de la época, para ya disponer la Introdvción para leer y pronunciar bien las lenguas Tofcana $y$ Caltellana con una extensión de seis páginas.

La obra se presenta dividida en dos partes: PRIMERA PARTE /DEL VOCABVLARIO DE LA / LENGVA TOSCANA Y / CASTELLANA, que abarca 282 páginas $^{16}$, con unas 18.300 entradas $^{17}$; SEGVNDA PARTE / DEL VOCABVLARIO DE LAS / DOS LENGVAS CASTELLANA / Y TOSCANA DE CHRISTOVAL / DE LAS CASAS. / DONDE SE CONTIENE LA DE- / claracion de Caltellano en / Tolcano, con una extensión de 184 páginas $^{18}$, con unas 10.100 entradas $^{19}$. Por el número de voces contenidas en ambas partes, la obra de Las Casas se despega de la trayectoria de los vocabularios y nomenclaturas existentes hasta el momento, e inaugura la tradición de los diccionarios extensos bilingües italiano-español que culminará a finales del siglo XIX.

La construcción del diccionario de Las Casas sigue la forma acuñada por Nebrija, pues en la macroestructura de la primera parte, italiano-español, se observan tres características heredadas de él: una macroestructura no lematizada (dos entradas para la misma palabra: Datio $^{20}$. Rentero, alcaualero. Datio. Tributario, pág. $49^{21}$, o tres: Scarpello. Buril. Scarpello. Sinzel. Scarpello. Elcoplo, pág. 125); incluir las expresiones pluriverbales como entradas del diccionario (doce en el verbo dar: Dar berta. Burlar. Dar cozzo. Encontrar. Dar deggiare. Tirar dardo. Dar di cozzo. Encontrar. Dar di piglio. Tomar. Arrebatar. Dar ilgualto. Deltruyr. Dar le baie. Burlar. Dar le baie. Engañar. Dar le pelche. Conferir Jodomia la muger. Dar le Jpalle. Huyr. Dar opra. Trabajar. Darfi vanto. Loarfe, jatarfe,

\footnotetext{
${ }^{16}$ Realmente la obra va numerada por folios; esta primera parte tendría 141 folios que se corresponden con 282 páginas.

${ }^{17}$ El número total de entradas de esta primera parte se ha extraído ponderando la media de entradas por página tras un muestreo representativo de 20 páginas aleatorias del diccionario. El cómputo de las entradas ha sido (señalamos en primer lugar el número de la página y en segundo lugar el número de entradas de la página): 13: 48; 30: 63; 33b: 65; 40: 70; 44: 68; 50: 64; 56: 70; 58: 55; 78: 68; 79: 85; 83: 55; 85: 68; 95: 68; 99: 57; 108: 75; 111: 69; 117: 73 ; 124: 70; 135: 67; 153: 50. Gallina (1959) apunta una macroestructura más pequeña, pues dice que ascendería a 15.500 palabras.

${ }^{18}$ Al igual que en la primera parte, esta segunda también se numera por folios, con 92, por lo que serán 184 páginas.

${ }^{19}$ El número total de entradas de esta primera parte se ha extraído ponderando la media de entradas por página tras un muestreo representativo de 20 páginas aleatorias del diccionario. El cómputo de las entradas ha sido (señalamos en primer lugar el número de la página y en segundo lugar el número de entradas de la página): 155: 58; 159: 61; 161: $61 ; 175: 59 ; 182: 56 ; 186: 53 ; 201: 57 ; 203$ b: 57; 210: 55; 210b: 57; 218b: 51; 220: 48; 222: 58; 224: 63; 229b: 48; 232: 53; 236: 53; 239b: 56; $245: 60 ; 246 \mathrm{~b}: 40$.

${ }^{20}$ Para favorecer la comprensión, se usará siempre la letra negrita para señalar la voz incluida en la macroestructura y así diferenciarla mejor del resto de lo contenido en el artículo lexicográfico. En lo sucesivo siempre se hará así.

${ }^{21}$ El número de página de los ejemplos que se incluyen remiten a la edición que hemos señalado de 1570.
} 
pág. 49); respetar escrupulosamente el orden alfabético, pues en este listado de unidades pluriverbales, incluye las entradas Dardo y Dare en los lugares que les corresponde. Estas tres características no operan de la misma forma en la segunda parte, español-italiano, pues aunque la inclusión de las unidades pluriverbales sigue realizándose como entradas independientes (Dar color. Adogliare. Dar carena. Rimpalmare, Jpalmare. Dar leche. Allatare. Dar à cambio. Acciuire. Dar por ninguno. Annullare, pág. 181) y también se sigue un estricto orden alfabético en su presentación, no ocurre lo mismo en cuanto a la lematización pues, ahora, sí que la presenta de forma exhaustiva.

Es posible que esta diferencia importante entre las macroestructuras de las dos partes se deba a las diversas fuentes utilizadas por Las Casas para la realización de su diccionario. En la parte italiano-español careció de un corpus o de un modelo definido, mientras que, en la segunda parte, español-italiano, contó con la obra de Nebrija como sustento y guía, sobre la cual operaría en la labor de selección del léxico que iba a introducir como entradas en su diccionario (Gallina 1959, Lope Blanch 1990, Acero 1991, Guerrero 1995). Por este motivo, la parte español-italiano contiene muchas menos entradas que su fuente ya que no incluye ni los nombres propios ni el léxico poco significativo para la lengua estándar, a lo que habría que añadir el que el español no contaba con la precisión semántica que Nebrija observaba en el latín (Nieto Jiménez 1992, Martínez Egido 2002).

La construcción de la microestructura es muy escueta, al igual que lo era la del Vocabulario de Nebrija. Se limita en la mayoría de los artículos a ofrecer la equivalencia en la lengua de salida (Imbecilità. Flaqueza, pág. 75. Danzar. Danzare, pág. 181) y, en algunos casos, a ofrecer una serie de sinónimos (Conciatore. Adereçador. Adobador, pág. 43. Acompañar. Accomitare, accompagnare, a $\int$ occiare, a $\int$ otare, binare, conpagnare, pág. 156). Solamente, en aquellas voces en que la equivalencia no es posible en la lengua de salida opta por ofrecer una definición perifrástica (Fomentatione. Emplalto de cocimiento, pág. 64. Immillare. Multiplicar por millares, pág. 76. Terrigena. Na cido de la tierra, pág. 143). Y también, en contadas ocasiones, podemos encontrar ambas, la equivalencia y la definición perifrástica (Confinare. Alindar, poner termino, pág. 43. Timpani. Atabales, caxas de atambor, pág. 144). Por último, resta añadir, en la descripción de la operatividad de la microestructura del diccionario de Las Casas, que en algunas entradas incluye el hiperónimo de ellas (Nipotella. Neuadera yerua, pág. 97. Tigre. Tigre animal, pág. 144. Tiglia. Teja arbol, pág. 144), siendo ésta la única información que se permite añadir a lo largo de toda la obra y que ya también constataba Nebrija.

El valor del Vocabulario de las dos lenguas toscana y castellana de Cristóbal de Las Casas es indiscutible, tanto por haber sido el primer gran diccionario bilingüe españolitaliano de la historia, como por el éxito alcanzado entre el público a juzgar por las 16 ediciones que tuvo, desde la primera de 1570 hasta la última de $1622^{22}$. Tanto su importancia como su utilidad se vieron apagadas tras la publicación en 1620 del

\footnotetext{
${ }^{22}$ Gallina (1959) da cuenta de las ediciones de la obra, así como San Vicente (2008): 1570, Sevilla; 1576, Venecia; 1579, Sevilla; 1582, Venecia; 1583, Sevilla; 1587, Venecia; 1591, Venecia; 1594, Venecia; 1597, Venecia; 1600 Venecia; 1604, Venecia, 1608, Venecia; 1613; 1618, Venecia; 1618; 1622, Venecia.
} 
vocabulario de Lorenzo Franciosini, obra que estaba llamada a perpetuarse en el tiempo como el gran diccionario bilingüe español-italiano.

\section{LA LEXICOGRAFÍA BILINGÜE ESPAÑOL-ITALIANO: EL SIGLO XVII}

\subsection{Actividad lexicográfica}

El siglo XVII se configura como la centuria en la que se consolida toda la práctica lexicográfica bilingüe que ha venido gestándose en el siglo anterior, tanto en lo relativo a los pequeños diccionarios o nomenclaturas, con la publicación de las mismas series de obras ya apuntadas u otras nuevas que aparecen añadidas a gramáticas u obras destinadas a la enseñanza de lenguas extranjeras (Alvar Ezquerra 1995), como a la aparición de diccionarios extensos, pues a comienzos de la centuria el español ya posee grandes diccionarios con las principales lenguas del occidente europeo: con el italiano, la obra de Las Casas de 1570; con el inglés, las obras de Percyvall, Bibliotheca Hispanica de 1591 (Martín Gamero 1962), y Minsheu, A dictionarie in spanish and english de 1599 (Martín Gamero 1962), y con el francés con los diccionarios de Palet, 1604 ${ }^{23}$ (Cooper 1962), y de Oudin, $1607^{24}$ (Guerrero 1990, Martínez Egido 2002b); incluso también se publicará una gran obra trilingüe español-francés-italiano, de Girolamo Vittori, en $1609^{25}$ (Cooper 1960).

A ello habría que añadir la aparición del primer diccionario monolingüe de español, el Tesoro de la lengua castellana o española de Sebastián de Covarrubias en 1611 (Lépinette 1989, Azorín 2000: 97-158, Azorín 2006). Su publicación supone un hito en la historia de la lexicografía española ya que, aunque no fue concebido ni planificado como un diccionario general de lengua, sino como una obra etimológica y casi enciclopédica, rebasó ampliamente su propia concepción y se adelantó un año a la publicación del Vocabulario degli Accademici della Crvsca ${ }^{26}$, primer gran diccionario monolingüe de italiano. El Tesoro de Covarrubias fue el primer y único diccionario monolingüe de español durante más de un siglo, hasta que, ya entrado el siglo XVIII, la Academia Española publicara su Diccionario de Autoridades.

E1 Tesoro de Covarrubias, tanto por el número y la calidad de las entradas que ofrece, como por la extensa microestructura que desarrolla, se convertirá en fuente valiosa e inevitable para todas las obras lexicográficas que se publiquen posteriormente, incluido el ya mencionado diccionario académico.

En su vertiente etimológica y parcialmente enciclopédica, tuvo como antecedente directo el Origen y etymología de todos los vocablos originales de la Lengua Castellana de

\footnotetext{
${ }^{23}$ Diccionario muy copioso de la lengua española y francesa, París, M. Guillemet, 1604.

${ }^{24}$ Tesoro de las lenguas francesa y española, París, Marc Orry, 1607.

${ }^{25}$ Tesoro de las tres lenguas francesa, española e italiana, Ginebra, Ph. Albert \& A. Pernet, 1609.

${ }^{26}$ Accademici della Crusca, Vocabulario degli Accademici della Crvsca, con tre indici delle voci, locuzioni, e prouerbi latini, e greci, posti per entro l'opera, Venecia, G. Alberti, 1612.
} 
Francisco del Rosal ${ }^{27}$ (Gómez Aguado 1992) que data de 1601. Aunque este trabajo nunca fue publicado, debió difundirse como obra manuscrita pues, hasta nuestros días, han llegado diferentes copias. De las cuatro partes de que consta la obra, el diccionario como tal ocupa la primera con unas 10000 voces en su macroestructura y con una microestructura con diferentes informaciones relativas a marcas lexicográficas, como voces relativas a profesiones, voces rústicas, dialectalismos, etc. (Azorín 2000: 105-108).

\subsection{La producción lexicográfica bilingüe español-italiano}

Durante el siglo XVII la producción lexicográfica bilingüe español-italiano de diccionarios extensos se circunscribe solamente a la última edición del Vocabulario de Las Casas aparecida en 1622 y a la publicación del diccionario de Lorenzo Franciosini en 1620 con sus posteriores reediciones, pues esta obra alcanzará un éxito sin precedentes en toda la historia de la lexicografía bilingüe de las lenguas de Europa occidental, ya que se convertirá en el diccionario bilingüe español-italiano por excelencia durante casi doscientos años.

El diccionario se divide en dos volúmenes, el primero o parte prima comienza con la portada siguiente:

Vocabolario / Italiano, e Spagnolo / non piv dato in luce. // Nel quale con la facilità, e copia, / che in altri manca, si dichiarano e con proprietà conuer- / tono tutte le voci Toscane in Castigliano, e le / Castigliane in Toscano. // Con le Frasi, et alcuni Prouerbi, che in ambe due le lingue giornalmente / occorrono; con un chiara, e breue Regola per leggere, e scri/uere, et una succinta Introduzione, con Auuertimenti / di molte cose notabili. // Opera vtilissima, e necessaria a' Predicatori, Segretari, e Traduttori. / che con legittimo senso, e vero fondamento le voglion / tradurre, o imparare. // Composto da / Lorenzo Franciosini Fiorentino. // Parte prima. // In Roma, A spese di Gio. Angelo Ruffinelli. \& Angelo Manni. // Appresso Gio. Paolo Profilio. MDCXX. Con licenza, e priuilegio de' Superiori. ${ }^{28}$

El texto consta de 668 páginas más la portada que se ha ofrecido y 7 páginas que contienen los preliminares: la nota del "Imprimatur", y las dedicatorias ALL'ILLVSTRISS. E REVERENDISS. SIG. / IL SIGNOR / CARDINAL BORGHESE / SIG. MIO COLENDISS, ambas firmadas por el autor. Las dos primeras páginas comprenden la REGOLA / PER LEGGER, E SCRIVERE / IN LINGVA CASTIGLIANA, con la información distribuida en dos columnas. A continuación, hasta la página 34, se incluye la INTRODVZIONE / ALLA LINGVA SPAGNOLA que intenta ser una aproximación muy rudimentaria a una gramática del español. En ella, el lexicógrafo expone algunas cuestiones que puedan ofrecer alguna dificultad al hablante italiano que quiere aprender español y, por ello, ofrece algunos modelos de declinación de adjetivos o artículos o ciertos paradigmas verbales (Martínez Egido 2002a: 126-135).

\footnotetext{
${ }^{27}$ El manuscrito se encuentra en la Biblioteca Nacional bajo la signatura: Ms 6929-T.127. El Alfabeto primero se encuentra publicado en edición facsimilar: F. de Rosal, Diccionario etimológico, E. Gómez Aguado (ed.), Madrid, C.S.I.C., 1992.

${ }^{28}$ En lo sucesivo, siempre que citemos informaciones recogidas por Franciosini, remitiremos a esta edición mediante la constatación del número de página entre paréntesis, indicando a continuación si se trata de la primera parte con $I$, y si se trata de la segunda parte con $I$.
} 
La segunda parte, español-italiano, comprende el segundo volumen del Vocabulario y tiene como portada:

VOCABOLARIO / ESPAÑOL, E ITALIANO / AHORA NVEVAMENTE SACADO A LVZ, / Y COMPVUESTO / Por / LORENZO FRANCIOSINI FLORENTIN. / Segunda Parte. / EN ROMA, A costa de Iuan Angel Rufineli, y Angel / Manni. MDCXX. / Por Iuan Pablo Pofilio. Con licencia, y Priuilegio.

Después aparece la nota del Imprimatur, seguida por la dedicatoria al ILLVSTRISS. Y REVERENDISS. SEÑOR / DON / FRANCISCO ORSINO / ABAD DE FARFA / MI SEÑOR, que ocupa dos páginas. Sigue con una nota al lector firmada por el propio Lorenzo Franciosini, en la cual, según el estilo de todos los libros de la época, declara su humildad y se disculpa por su poco saber en esta labor que ha emprendido, a la que le siguen el Privilegio, redactado en latín, y la REGLA / PARA LEER / ITALIANO con una extensión de seis páginas. Aquí incluye diferentes materiales como son las diversas observaciones sobre la pronunciación de diferentes sílabas en italiano, los artículos en la lengua latina y las conjugaciones de los verbos. Todo este tipo de información ofrecida se enmarca en la norma editorial de la época, por lo que todas las informaciones gramaticales que expone no son más que elementos de referencia, concebidos para ayudar al destinatario en su labor de aprendiente de italiano (Martínez Egido 2002a: 136-140).

El éxito de este diccionario se debió a que su autor reunió en la realización de su diccionario una serie de características que lo dotaron de una gran practicidad para el usuario. El número de entradas que conforman las macroestructuras de sus dos partes es muy elevado, si lo comparamos con la obra de Las Casas, ya que registra 26.229 en la primera, italiano-español, y 35.138 en la segunda parte, español-italiano, (Martínez Egido 2002a: 141-163). No posee tampoco, como todos sus antecesores, un criterio claro para el tratamiento de lo que debe ser la unidad lexicográfica (Alvar Ezquerra 2002), por lo que su macroestructura además de no encontrarse lematizada, contiene diversas expresiones pluriverbales, tanto sintagmáticas (palla di legno, pág. 433, I; tanto per tanto, pág. 610, I; lado die tro, pág. 460, II; nalgada de tocino, pág. 529, II) como oracionales (rabbrufcar'il tempo, pág. 494, I; racorre nell'abbaco, pág. 492, I; abaratar las mercadurias, pág. 7, II; nadar con calabaça, 528, II) (Martínez Egido 2002a: 164-226).

Donde se distingue y se separa ampliamente de sus precedentes lexicográficos bilingües es en la configuración y redacción de la microestructura. En ella no se limita a ofrecer la equivalencia o una perífrasis definitoria en la lengua de salida, sino que aporta otros tipos de información, no sólo en la lengua de salida sino también en la propia lengua de entrada, tanto en la primera como en la segunda parte de su diccionario, aunque siempre es mucho más prolijo en lo aportado en italiano. Este hecho convierte al Vocabulario en un diccionario semibilingüe, sobre todo de italiano, ya que, aunque su finalidad primordial no haya sido ésta, puede ser utilizado como tal, como podemos comprobar en los siguientes ejemplos, ya que en el primero ofrece cuatro sinónimos en la lengua de entrada más una pequeña definición e, incluso, una marca de uso y en el segundo ejemplo, en la lengua de salida, también el italiano, proporciona la equivalencia más una caracterización del animal:

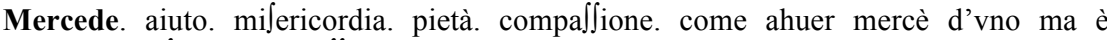
poetico. [tener la ltima. compa $\iint i o n$, o mancilla de otro. (Pág. 390, I) 
Luziernaga. [lucciola, animaletto che battendo l'ali rallumina le tenebre. (Pág. 478, II)

En la primera parte, italiano-español, el número de entradas que poseen información en italiano asciende al $82,15 \%$. Los tipos de información añadida son: gramatical (bacherozzolo, diminutivo de baco [gusanillo], pág. 105, I); equivalencias ( $\boldsymbol{A}$, in vece di a

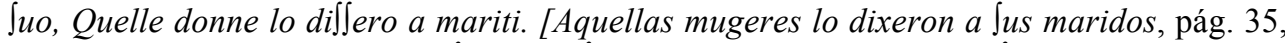
I); sinónimo o sinónimos (Illu〕ione. falla. finta. \& inganeuol, raprefentazione. [engaño, ilulion, pág. 313, I); usos (cacare, più honeltamente, si dice fal del corpo. [hazer camara.

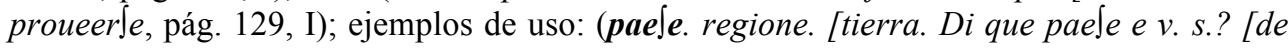
que tierra es v. m.?, pág. 431, I). Además, todos estos tipos pueden repetirse en un mismo artículo lexicográfico y pueden combinarse de diferentes formas entre $\mathrm{si}^{29}$. En la lengua de salida, Franciosini también ofrece una enorme variedad en lo que aporta, aunque predomina la traducción directa de la entrada ya que un 83,85 \% (Martínez Egido 2002a) la poseen (cacciatore, colui che caccia fiere. [caçador, pág. 129, I), no obstante, en otras muchas ocasiones, ésta aparece combinada con otras posibilidades como puede ser una definición (saluare, o trar di pericolo. [Sacar i librar a vno de vn peligro. saluar, pág. 529 I).

En la segunda parte, español-italiano, ocurre lo mismo que en la primera, aunque el número de entradas que presentan información añadida en español como lengua de entrada es muy escaso, $15,96 \%$, respecto al número de entradas que la presentan en italiano como lengua de salida, 76,95 \% (Martínez Egido 2002a). Los tipos de información coinciden en general con los observados en la primera parte del Vocabulario. Ejemplos de la lengua de partida son: gramatical (ramal o ramales, pág. 625, II), sinónimos (cabeçalero. te tamentaio o albacèa, pág. 124, II) valores de uso (yantar. Vocablo antico, pág. 437, II), ejemplos de uso (paciencia. [...] lleuar \us trabajos con paciencia, pág. 550, II), remisiones al propio diccionario (cabali]tico. Vedi cabala, pag. 123, II) y cuestiones ortográficas (baul o bahul, pág. 90, II). En la lengua de salida, el italiano, ejemplos de información añadida son: gramatical (Da. [...] terza perfona del nuemro del meno dell'indicatiuo del verbo dare, pág. 227; ramal o ramales, pág. 625, II), sinónimos (ra]guño, [...] [grafitura. Graffio, pág. 627, II), valores de uso (o que lindo. [...] modo di dir'ironico, pág. 437, II), ejemplos de uso (caca. [cacca, voce qui v lano le balie quando voglion che i lor bambini non tocchino, o magino vna cola gli dicono es caca. [vale è cacca, cioè merda, pág. 127, II), remisiones al propio diccionario (bayladora. [è l'i i te $\iint_{o}$ che byladera, e baylarina, pág. 90, II).

Todas estas informaciones añadidas sólo tienen el único denominador común de ser muy abundantes a lo largo de toda la obra. Su distribución es anárquica pues no se sigue ningún patrón preestablecido para incluir la clase de información ni tampoco su disposición en el desarrollo de la microestructura (Martínez Egido 2002a).

Esta misma característica se observa en la inclusión de las expresiones pluriverbales, ya que éstas pueden aparecer como entradas en la macroestructura (como en los ejemplos ya vistos), que son los más numerosas, o como parte integrante de la microestructura $\mathrm{y}$, todo ello, sin ningún tipo de criterio que dilucide su inclusión en una o en otra parte del artículo

\footnotetext{
${ }^{29}$ Ejemplos de toda la casuística que se puede encontrar en el desarrollo de la microestructura del Vocabulario, véase Martínez Egido (2002a: 227-299).
} 
lexicográfico. La guía para su incorporación al diccionario y su posterior colocación en una parte u otra del artículo se debe a la práctica artesanal de la época, diseñada para servir al público destinatario del trabajo, por ello no actúan criterios como la fijación, la idiomaticidad o la forma de los sintagmas y de los enunciados, sino la utilidad que van a tener para el hablante extranjero o el traductor (Martínez Egido y Ruiz Gurillo 2004: 1064). A su vez, esta utilidad se ve potenciada por la aparición de un número elevadísimo de estas unidades pluriverbales, sobre todo si se comparan con las incluidas en las obras lexicográficas anteriores ${ }^{30}$ (Martínez Egido y Ruiz Gurillo 2004, Ruiz Gurillo y Martínez Egido 2006).

Resulta claro pensar que la labor ingente realizada por Lorenzo Franciosini debió estar motivada, además de por su buen hacer como maestro de lenguas (Martínez Egido 2006a), por un manejo correcto y abundante de las diferentes fuentes que ya estaban a su disposición. La macroestructura en italiano de su primera parte, tras el estudio realizado (Martínez Egido 2002a: 304-319), procede en un 58,62 \% del diccionario de La Crusca y en un 34,12\% del diccionario de Las Casas, mientras que el 34,52\% sería original de Lorenzo Franciosini. Ahora bien, este último porcentaje descendería, tras una exhaustiva lematización, solamente a un 8,86 \% (Martínez Egido 2002a). En lo referente a la macroestructura de la segunda parte, español-italiano, comparte con el resto de los diccionarios extensos anteriores a él los siguientes porcentajes: 67,65\% con Oudin, 64,60 $\%$ con Vittori, 48,16\% con Minsheu, 44,21 \% con Palet, 37,92 \% con Covarrubias, un $35,44 \%$ con Percyvall, 30,41 \% con Nebrija y 34, $75 \%$ con Las Casas. Las entradas originales de Franciosini representarían un 15, $33 \%$ que, tras el proceso de lematización, quedarían reducidas a un 2,53\%. Tras estos resultados (Martínez Egido 2004) puede concluirse que la originalidad del Vocabulario no radicaría en su aspecto cuantitativo, como aparentemente podría parecer, sino en el triple procedimiento llevado a cabo por el lexicógrafo sobre las fuentes a su disposición: rechazar las entradas que no le interesan, desarrollar mediante diferentes procesos unas y ofrecer la inclusión como novedad de otras (Martínez Egido 2002a: 301-341).

Respecto a las fuentes que el lexicógrafo italiano utilizó para la confección y redacción de su microestructura, en lo que respecta a lo incluido en italiano en la primera parte su base fundamental es el diccionario de la Crusca, ya que sobre la información que ofrece este diccionario, Franciosini opera reestructurándolas de diferentes formas (Martínez Egido 2002a: 371-378) para luego traducirlo todo en español como lengua de salida. Este mismo procedimiento es el que utiliza en la segunda parte con el español como lengua de entrada, pero en esta ocasión, la fuente directa y más importante es el Tesoro de Covarrubias (Martínez Egido 2002a: 378-453, Martínez Egido 2003), mientras que la coincidencia con

${ }^{30}$ Del $10 \%$ de las entradas seleccionadas para la descripción de la parte español-italiano del Vocabulario (Martínez Egido 2002), un 25,56 \%, 899 entradas, constituyen unidades pluriverbales. Para observar la diferencia cuantitativa de Franciosini respecto a las obras anteriores, en las ediciones ya anotadas en este trabajo, se compararon con las incluidas por ellas en la misma cala. Los resultados fueron evidentes: Franciosini, 899; Oudin, 336; Vittori, 287; Nebrija, 222; Minsheu, 199; Covarrubias, 149; Percyvall, 142; Palet, 120; Las Casas, 76 (Martínez Egido y Ruiz Gurillo 2004). Estos datos todavía resultan más evidentes en la comparación, entre todas las obras mencionadas, de las unidades pluriverbales incluidas en los verbos dar, echar, saber y sacar (Martínez Egido y Ruiz Gurillo 2006). 
el diccionario de Oudin es mucho menor, a pesar de haber sido su antecedente más inmediato con la edición de 1616, considerada durante mucho tiempo como su fuente principal. Las obras de Cesar Oudin siempre fueron sus referentes pero Lorenzo Franciosini no las copió (Martínez Egido 2002b).

Ejemplos de artículos lexicográficos completos de este diccionario, tanto de la primera parte italiano-español como de la segunda parte español-italiano, que ilustren de forma general todo lo expuesto sobre el Vocabulario de Lorenzo Franciosini serían:

dote, o dota. quello che dà la moglie al marito per foltentamento del carico matrimoniale. [dote.] Di ceua vno, il Padre da la dote, e Dio la buona moglie. [Dezia vno, el Padre $\int$ dà el dote, y Dios la buena muger. (Pág. 239, I)

perdere, il contrario di vencer, es'intendel del giuoco. [perder] Vn Dottor di legge hauerua per $\int_{0}$ di molti danari alle carte, e rimafe me $\int$ colandole, como ò vfanza di chi hà perfo. domandandogli vno quelo che lui faceua? rilpole. Sto guardando in che cofa $\int_{i}$ errò que to proce $\iint_{0}$. [Vn letrado auia perdido muchos dineros a los naipes, y quedo $\iint \mathrm{e}$ barajando, como es coltumbre de los que han perdido, preguntándole vno que hazia?

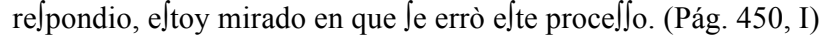

dote. [dote che $\int i$ dà nel maritar la figliuola. (Pág. 287, II)

perder. [perderé. (Pág. 574, II)

Con todas estas consideraciones, es indudable que el Vocabulario tuviera un éxito importantísimo y se convirtiera en el diccionario bilingüe italiano-español por excelencia durante todo el siglo XVII e, incluso, en toda la centuria posterior, y que no apareciera en el mercado ninguna otra obra que pudiera hacerle algún tipo de competencia. Lorenzo Franciosini construyó un diccionario moderno, concibió un producto muy útil ya que podía ser utilizado tanto como un diccionario bilingüe español-italiano, como un diccionario monolingüe en cada una de sus lenguas por las ricas informaciones con las que dotó a cada una de sus entradas. Testimonio de ello fue el hecho de que se editara en lo que restaba de la centuria en siete ocasiones más ${ }^{31}$, sin ningún tipo de añadido importante ni reelaboración ${ }^{32}$.

\section{LA LEXICOGRAFÍA BILINGÜE ESPAÑOL-ITALIANO: EL SIGLO XVIII}

\subsection{Actividad lexicográfica.}

La actividad lexicográfica bilingüe entre el español y el italiano durante toda esta centuria es verdaderamente escasa, sobre todo si se compara con la habida en los dos siglos anteriores y con la producción monolingüe en español o con el desarrollo de la lexicografía bilingüe español-francés del momento. Respecto a la primera, destaca la labor realizada por

\footnotetext{
${ }^{31}$ Las seis ediciones fueron: 1633; Ginebra, 1636; 1637; Roma, 1638; Venecia, 1645; Ginebra, 1665; Ginebra, 1666.

${ }^{32}$ Los pequeños añadidos o reestructuraciones pueden verse analizados en Gallina (1959) y Martínez Egido (2002a).
} 
la Real Academia Española con la publicación del Diccionario de Autoridades (1726-1739) (Ruhstaller 2003: 263-280), la reedición del tomo correspondiente a las letras A y B en 1770, el suplemento de 1780 y su reedición en 1783 y el diccionario común o usual en un sólo tomo que la Academia publicó en 1780 y que reeditó en 1783 y en 1791 . Fuera del ámbito de la lexicografía académica es imprescindible destacar la aparición del Diccionario castellano con las voces de ciencia y artes del jesuita P. Terreros y Pando ${ }^{33}$, tanto por ser el único diccionario general del español fuera de la esfera de la Academia como por incorporar entradas pertenecientes al ámbito profesional y cultural. Por otra parte, la lexicografía del español con la lengua francesa se ve completamente desarrollada con la publicación de seis importantes diccionarios que reflejan la trayectoria lexicográfica bilingüe en ambas lenguas; nos referimos a las obras de Sobrino ${ }^{34}$, Torre Ocón ${ }^{35}$, Herrero ${ }^{36}$, Séjournant ${ }^{37}$, González de Mendoza ${ }^{38}$ y Gattel $^{39}$.

\subsection{La producción lexicográfica bilingüe español-italiano}

El desarrollo de la lexicografía bilingüe español-italiano en esta centuria se circunscribe sólo a las reediciones del Vocabulario de Lorenzo Franciosini por una parte, y por otra parte a la publicación en 1771 de Las reglas a cerca de la lengua toscana o italiana de Estevan Rosterre ${ }^{40}$ y de Los tres alfabetos frances, latino é italiano en 1793 de Esteban de Terreros y Pando ${ }^{41}$.

Puede afirmarse que la obra de Franciosini será el diccionario bilingüe español-italiano, italiano-español por excelencia durante todo el siglo XVIII con seis ediciones en el mercado (Gallina 1959: 274-283, Martínez Egido 2002: 108-124). La primera de ellas es publicada en Ginebra en 1706 con la siguiente portada:

Vocabolario / Italiano, e Spagnolo: / Novamente dato in Luce: / Nel quale conla facilità e copia, / che in altri manca, si dichiarano, e con proprietà con- / vertono tutte le voci Toscanne in Castigliano, e le Casti- / gliane in Toscano. / Con le frasi, ed alcuni proverbi / che in ambe le lingue giornalmente occorrono; con una / chiara e breue regola per leggere e scrivere, una succinta / Introduzione, et Avvertimenti di molte cose notabili. / Opera utilissima, e necessaria à / Predicatori, Segretari, e Traduttori, che con legittimo senso, / e vero fondamento le vogliono tradurre, o imparare: / Composto da Lorenzo Franciosini /

\footnotetext{
${ }^{33}$ Madrid, Viuda de Ibarra, 1786-1793, 4 vols. Edición facsímil con prólogo de M. Alvar Ezquerra, Madrid, ArcoLibros, 1987.

${ }^{34}$ Diccionario nuevo de las lenguas española y francesa, Bruselas, F. Foppens, 1705.

${ }^{35}$ El maestro de las dos lenguas. Diccionario español y francés; francés y español, Madrid, 1728-1731.

${ }^{36}$ Diccionario universal, francés y español, Madrid, Imprenta del Reyno, 1744.

${ }^{37}$ Nouveau Dictionnaire espagnol-français et latin, 1749.

${ }^{38}$ Diccionario General de las dos lenguas española y francesa, Madrid, A. Ortega, 1761.

${ }^{39}$ Nouveau dictionnaire françois-espagnol et espagnol-françois, Lyon, Bruyset Freres, 1790.

${ }^{40}$ Forli, A. Marozzi.

${ }^{41}$ TOMO QUARTO Y ÚLTIMO DEL DICCIONARIO, Madrid, B. Cano.
} 
Fiorentino; / E da molti errori, in quest'ultima Edizione, purgato. / Genevra, / Appresso gli Associati. / M.DCCVI.

Vocabulario / Español / e Italiano, / Compuesto por / Lorenzo Franciosini / Florentino; / Nuevamente sacado à Luz, y de muchos / errores purgado. / Segunda parte. ${ }^{42}$

Todos los preliminares que acompañan a esta edición son exactamente iguales a los que se introducían en la de 1620, salvo en la actualización de las fechas de la publicación. No es cierto que haya sido purgada de diferentes errores, como se anuncia en el prólogo, ya que sigue directamente la edición de 1620 por lo que es una reimpresión directa de aquella ${ }^{43}$, al igual que la aparecida también en Ginebra un año después, en 1707.

La tercera edición en esta centuria vio la luz en 1735 en Venecia ${ }^{44}$ y solo presenta unas variaciones de forma al sustituir el grafema $u$ por el grafema $v$ y empezar la traducción con letra mayúscula. Sigue fiel a la edición de 1620, aunque recoge alguna de las pequeñas peculiaridades de las ediciones de 1638 y $1645^{45}$. Las tres ediciones restantes, publicadas en Venecia, en 1763, en 1774 y en 1796 respectivamente, son reimpresiones de la aparecida en 1735 .

Estas seis ediciones del Vocabulario de Lorenzo Franciosini no dejan de ser casi meras reimpresiones de la príncipe de 1620 pero, aún así, satisficieron las necesidades del público que necesitaba aprender español o italiano como lenguas extranjeras ya que el hecho de que ningún otro lexicógrafo publicara un diccionario bilingüe español-italiano así lo corrobora.

De otra parte, junto al ámbito estrictamente lexicográfico, en 1771, el jesuita español Esteban de Terreros y Pando presbítero (Niederehe 2005: 193) publicó bajo el anagrama de Esteban Rosterre, al estar exiliado en Forli a causa de la expulsión de los jesuitas de España en 1767 , Reglas a cerca de la lengua toscana o italiana ${ }^{46}$. Esta obra pertenece al bloque de

${ }^{42}$ Existe un ejemplar de esta edición en la Biblioteca Nacional, cuya signatura es 3/19083-84, que es el que nosotros hemos utilizado para realizar este cotejo.

${ }^{43}$ Incluso el topónimo Badajoz, que en la edición de 1620 aparece sin la $z$ final, seguramente por un error de imprenta y que es corregido en todas las reediciones del siglo XVII, aquí vuelve a aparecer sin esa letra $z$.

${ }^{44}$ Aunque en las fichas de la Biblioteca Nacional de Madrid conste la existencia de una edición en 1724 publicada en Venecia de este Vocabulario, realmente se trata de un error en las fichas, pues los ejemplares que poseen esa signatura en la $\mathrm{BN}$ son en realidad de la edición de 1774 publicada también en Venecia, tal y como hemos comprobado. En esta biblioteca existe un ejemplar de esta edición, que es el hemos utilizado para el cotejo y cuya signatura es 2/60463-4

${ }^{45}$ Particularidades como introducir también la entrada baguido en la macroestructura, pero no la define como se hacía en esas dos ediciones mencionadas sino que simplemente remita a vaguido. Incluye otra entrada pero en femenino lagareta, por lo que seguiría a la de 1645 en lugar de a la de 1638. También contempla algunos de los añadidos a la microestructura: en la entrada balteo añade lo que las otras anteriores banda; en la entrada Morderfe el labio se incluye en ella che tratta in fe fteffo di fara vendetta; en la entrada Hazerse à un lado introduce el mismo añadido que hemos señalado Scansarsi. Y como diferencia con todas las ediciones anteriores solamente se puede señalar que en la entrada hablar combina parte de lo aparecido en la edición de 1620 y de 1638: hablar. [...] haviamo [...] hoggi [...] voftri, o fopri di voi. (1620); hablar.[...] habbiamo [...] oggi [...] voftri, o di voi. (1638); hablar.[...] habbiamo [...] hoggi [...] voftri, o fopra di voi. (1735).

${ }^{46}$ En la portada, además de los datos de la edición, se explica el contenido del libro: REGLAS / A CERCA DE LA LENGUA TOSCANA, / O ITALIANA, / reducidas a metodo, y diltribuidas en cuatro / libros, incluido en ellos un 
las publicaciones destinadas al aprendizaje de lenguas extranjeras tan comunes desde el siglo XVI en el panorama europeo y que se inserta en la tradición de las Nomenclaturas ya descrita anteriormente (Martínez Egido 2006: 1099-1101). Dentro de este trabajo misceláneo, concretamente en el capítulo II que abarca desde la página 328 hasta la 398, ofrece una Coleccion, o relumen de los nombres, y verbos mas necelarios para la lo veion y converfaciones ordinarias: y le note, que algunos pueden pertenecer a varias clales, $y$ repetirfe tal ver por elta caula. Esta colección o resumen es en realidad una serie de agrupaciones temáticas tal y como se venían realizando tradicionalmente desde la Edad Media y que se contenían en vocabularios y nomenclaturas, por lo que no es un diccionario de lengua.

La técnica que utiliza para desarrollar estas agrupaciones es la misma ya constatada que arranca desde el siglo XV y que consiste en distribuir el material en dos columnas, a la izquierda el español como lengua de entrada y a la derecha el italiano como lengua de salida, en la que se limita a ofrecer la traducción directa. Cada agrupación va precedida de una presentación en español y traducida también al italiano como se puede observar en el siguiente ejemplo ${ }^{47}$ :

$\begin{array}{cc}\text { Nombre de las cofas mas } & \text { Nomi delle cofe più comuni } \\ \text { Comunes para comer, \&c. } & \text { per mangiare, \&c. } \\ \text { Agua, } & \text { acqua, } \\ \text { Afado, } & \text { Arro to, } \\ \text { Ave, } & \text { Uccello, } \\ \text { Caldo, Jubftancia, } & \text { Un brado, } \\ \text { Carne, } & \text { Della carne, } \\ \text { Carne manida, cocida, cruda, } & \text { carne frolla, cotta, cruda, } \\ \text { Caza, } & \text { caccia, Jalvaggina. } \\ {[\ldots . .} & {[\ldots]}\end{array}$

Al no contar con una doble dirección, ya que solamente es español-italiano, es evidente que el alumno al que se dirige el autor es solamente al español ya que éste sería al único al que esta obra resultaría verdaderamente útil.

Las agrupaciones y el número de entradas ${ }^{48}$, que consigna en cada una de ellas, son:

\footnotetext{
Diccionario / familiar, algunos Dialogos, flores poe- / ticas, y Cartas milivas; con el fin / de facilitar a los Elpañoles el co- / nocimiento, y u Jo de elte / idioma. OBRA DEDICADA / AL SEÑOR MARQUES / FABRIZIO PAULUCCI / POR / D. ESTEVAN ROSTERRE, PRESBITERO. / En FORLI', enla Imprenta de Achiles Marozzi. / Con aprovazion

${ }^{47}$ El ejemplo se encuentra en las páginas 339-340.

${ }^{48}$ Es el indicado entre paréntesis.
} 
Del Cielo, Elementos (67); Tocante al tiempo y Eftaciones (42); Los días de la semana (7); Los meses (12); Fiestas (22); Dignidades Eclefiasticas (81); Cofas pertenecientes a la Igle $\int i a(104)$; Nombres de las cofas mas comunes para comer (33); Trastos para la mesa

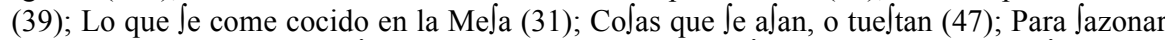
las viandas (26); Para la enfalada (19); Para los dias de Pe fcado (52); Frutas, o poltres (53); Grado de parentefco (66); Eltados del hombre, y de la mujer (34); Lo que Je necelita para veftirfe (44); Aditamento, y adorno del veftido (31); Para montar a caballo (51); Veftidos par las Mujeres (76); De las partes del cuerpo (154); Artes liberales, y Ciencias (42); Cofas pertenecientes al eftudio de las ciencias (42); Instrumentos de Mufica (27); De las partes de la cala (71); Muebles de la camara (44); Tra ftos de una chimenea, y ju circuito (25); Tra $\int_{\text {tos, }}$ y cofas de cocina (24); Cosas pertenecientes a la caba (22); Lo que fe halla en una puerta, y en $\int u$ circuito (10); Lo que Je halla en el eftablo, o caballeriza (23); Loque Je halla en un huerto, Jardin, flores, arboles (95); Nombres de Relijio os (16); Dignidades temporales (32); Cargos, y oficiales de Jufticia (14); Todo el confejo, o confejo pleno (32); Oficiales de guerra (49); Del Ejercito (28); Fortificaciones (46); Para un aledio (29); El mar, y algunos nombres de navios, y maniobras (50); Nombres de armas de guerra, y juftas (21); Pajaros (19); Animales de cuatro pies (22); Animales reptiles infectos (22); Colores (16); Metales (11); Para el eftudio (10); Para beber, comer (13); Para acoftarle (9); Para veftirje (5); Acciones comunes del hombre (26); Acciones de amor, y odio (22); Para las enfermedades (9); Para comprar (12); Acciones de movimiento (23); Acciones manuales (20); Acciones de la memoria, e imajinacion (18); Para las artes, y oficios (12).

Sumadas todas ellas, la recopilación realizada por el autor alcanza un total de 2102 unidades léxicas, número en consonancia con el que es habitual en este tipo de vocabularios concebidos como complemento léxico de otra obra de más envergadura, como se señalaba en el caso de las nomenclaturas, y, por ello, muy alejada de lo que fueron los grandes diccionarios bilingües de las centurias anteriores.

Unos años más tarde, entre 1786 y 1793, ahora sin anagrama, fueron publicados los cuatro volúmenes que conforman la obra Diccionario castellano con las voces de ciencias y artes, del P. Esteban de Terreros y Pando ${ }^{49}$ (Azorín y Santamaría 2004), casi veinte años después de su elaboración y ya fallecido su autor (Azorín 2000: 205-206). Los tres primeros tomos que aparecieron en 1786, 1787 y 1788 configuran un diccionario general del español, el único que se publica en el siglo XVIII sin el auspicio de la Real Academia de la Lengua y con el añadido de prestar una especial atención a las voces técnicas y profesionales (García Platero 2003: 263-281). El cuarto tomo, publicado en 1793, es un diccionario que contiene tres listados alfabéticos bilingües (latín-español, francés-español e italiano-español) que vienen a complementar a los tres tomos anteriores. Se configura así un diccionario bilingüe un tanto especial en la elaboración de su estructura, ya que al final de cada artículo lexicográfico de los tres tomos se constataban las equivalencias en esas tres lenguas, latín, francés e italiano, y ahora, en este cuarto volumen, se recogen algunas de esas equivalencias ${ }^{50}$ como lemario de cada uno de los tres alfabetos, es decir, las que eran

${ }^{49}$ E. Terreros y Pando, Diccionario castellano con las voces de ciencias y artes, Madrid, Viuda de Ibarra, 17861793, 4 vols. Edición facsímil con prólogo de M. Alvar Ezquerra, Madrid, Arco-Libros, 1987.

${ }^{50}$ En este sentido, haría falta un estudio exhaustivo de comparación entre las equivalencias dadas en los artículos de los tres primeros tomos y las entradas que configuran la macroestructura de los tres alfabetos, pues no sería extraño, como ha sucedido en otros casos de diccionarios bilingües, que no exista tal correspondencia. 
equivalencias en latín, francés e italiano en los tres primeros tomos se convierten en las lenguas de entrada en cada uno de los alfabetos respectivamente; son, por tanto, tres diccionarios bilingües unidireccionales, en los que la lengua de salida es siempre el español, agrupados en un único tomo ${ }^{51}$.

El vocabulario italiano-español de este cuarto volumen abarca 260 páginas ${ }^{52}$ a dos columnas y contiene un total de 33.800 entradas según nuestro cálculo estimativo ${ }^{53}$. La selección de las entradas, como ha señalado San Vicente $(2007)^{54}$, no procede de la lengua general, sino que derivan del metatexto castellano que se ha configurado en el diccionario contenido en los tres tomos anteriores. La disposición de todas las entradas que configuran su macroestructura no presenta una buena lematización, es decir, que, en numerosas ocasiones, diferentes acepciones de una misma unidad léxica aparecen como entradas diferentes, por lo que el número de entradas que contiene el Alfabeto realmente sería mucho menor que el consignado aquí tras la realización de una lematización correcta. Ejemplos de esta ausencia de lematización serían dardo, en dos artículos, y punto, con 13 artículos:

Dardo: Azagaya, tiro, dardo.

Dardo: Saeta, Dícese poeticamente de las palabras, ó atractivos del amor. (Pág. 43$)^{55}$

Punto, nomb. Subst. Punto, término de Jeometría, el que no tiene partes.

Punto. Punto, instante, momento.

Punto. Punto, señar al fin de un periodo. Far punto, Hacer punto, pararse.

Punto. Punto, proposición, conclusión.

\footnotetext{
${ }^{51}$ Esta concepción aparece expresada en la Advertencia que precede a los Alfabetos de la siguiente forma: "Este Tomo IV, comprehende, pues, las voces de Ciencias y Artes en las tres lenguas Francesa, Italiana y Latina, cuyas correspondencias expresó el Padre Terreros en el Diccionario Castellano; y es en efecto la reducción de éste á aquellas, obra que premeditó el Autor, y que con justísima razón la llama en el Prólogo el complemento de todas sus ideas" (1987: III).

${ }^{52}$ Se sigue la edición facsímil de 1987 con prólogo de Manuel Alvar Ezquerra.

${ }^{53}$ El cómputo total de entradas lo hemos extraído nosotros mediante el siguiente procedimiento: se han seleccionado 20 páginas del Alfabeto de forma aleatoria pero intentando que abarcaran toda la extensión del diccionario para que sean verdaderamente representativas. El cómputo de estas 20 páginas ha sido (señalamos en primer lugar el número de la página y en segundo lugar el número de entradas de la página): 1: 128;13: 124; 26: 132; 31: 136; 43: 127; 50: 125; 62: 111; 75: 146; 87: 144; 99: 145; 105: 139; 118: 115; 115: 146; 131: 138; 134 138; 144: 123; 173: 130; 183: 124; 209: 118; 260: 100. Después se ha obtenido la media de entradas por página y el resultado se ha multiplicado por el total de las páginas del Alfabeto.

${ }^{54}$ Felix San Vicente realizó una aproximación a la génesis, a la descripción y a la valoración final del Alfabeto italiano-español en su Ponencia invitada, "El diccionario castellano de E. Terreros y Pando y la Lexicografía plurilingüe", al congreso celebrado en la Universidad de Deusto, Bilbao, del 21 al 23 de noviembre de 2007, Esteban de Terreros y Pando: vizcaíno, poligrafo y jesuita ante los retos del siglo XIX. En prensa.

${ }^{55}$ Los números de las páginas que se consignan en los ejemplos se corresponde con la edición manejada y ya citada anteriormente.
} 
Punto. Punto, asunto, ó materia de que se trata.

Punto. Punto, articulo, arte de una instrucción.

Punto. Punto, lugar, ó pasaje de una ciencia, ó escrito.

Punto. Punto, término, estado, grado.

Punto. Cavilación, sofistería, sutileza.

Punto. Punto en el juego.

Punto. Puntada

Punto. nom. Adj. Participio pasivo del verbo Púgnere.

Punto. Adv. Nada. (Pág. 131)

Respecto a la construcción de la macroestructura también se observa una irregularidad en la inclusión de unidades pluriverbales, ya que hasta la página 95 del Alfabeto éstas se sitúan regularmente como entradas de la macroestructura y después lo harán en la microestructura casi de forma general ${ }^{56}$ como parte integrante del artículo lexicográfico, tal y como se muestra en el siguiente ejemplo, ya que Menar aparece con seis entradas diferentes, mientras que mentire, en una sola:

Menar donna, o moglie. Casarse.

Menar per lo naso. Llevar por las narices á uno, traherle engañado.

Menar le gambe. Huir, menear las tabas.

Menar fuori. Educir, sacar á fuera.

Menar delle calcagne. Lo mismo.

Menar le mani. Combatir, pelear i tomar un negocio con empeño. (Pág. 95)

Mentire, verb. Neutr. Mentir.

Mentir per la gola. Mentir descaradamente. (Pág. 95)

De estas observaciones puede deducirse que en la construcción de este Alfabeto no existió la uniformidad ya imperante en el siglo XVIII con la aparición del Diccionario de la Academia y que, por el contrario, sí que entronca con la tradición anterior de los diccionarios bilingües, concretamente con la configurada por Lorenzo Franciosini durante los siglos XVII y XVIII, tal y como aquí se ha mostrado.

Respecto a la microestructura del Alfabeto se advierte que la construcción del artículo lexicográfico es generalmente sencilla aunque tampoco es uniforme siempre. En la Advertencia de la obra ya se incide en este aspecto al decir: "me he contentado con expresar desnudamente las correspondencias castellanas sin explicación alguna de esas mismas" (1987: III). En general se limita a ofrecer la entrada seguida de la equivalencia en

${ }^{56}$ Habrá alguna excepción como en el caso de Notte di Natàle que aparece como entrada distinta de Notte (pág. 103). 
español (Adderente: Adherente, pág. 3), o bien con la equivalencia seguida de algunos sinónimos (Addormentare: Adormecer, engañar, burlar, pág. 3); en ocasiones ofrece una pequeña definición perifrástica cuando dicha equivalencia no puede darse (Addomesticare: Volver a suavizar, pág. 3); y en otras combina la equivalencia con la definición perifrástica (Adescare: Embaucar con lisonjas, cebar, engolosinar, ganar la voluntad, atraer, pág. 3).

Las informaciones añadidas, es decir, las aportaciones fuera de lo que son las equivalencias y las definiciones perifrásticas, ofrecidas en el desarrollo del artículo lexicográfico no son muy abundantes ni tampoco uniformes. Dentro de ellas se pueden distinguir cinco tipos:

1) información de la categoría gramatical de la entrada en casos muy esporádicos (Adagio, adv. Cómodamente, lentamente, suavemente, pág. 2; Noto, subst. Sud, ó sur, viento de medio dia, pág. 103);

2) indicaciones morfológicas, como en el caso de los diminutivos (Bassetto, dimin. De Basso, pág. 15);

3) remisiones a otras entradas del diccionario (Bacile. Véase Bacino, pág. 13; Baberia. Véase Barrería, pág. 15);

4) marcaciones de uso, tanto diafásicas (Basina, voz baja. Bazofia, pág. 15), como diatécnicas (Concetrazione. Reconcentración, término de Física, pág. 36; Ireos. Iris, término de Jardineros, ó Floristas, lirio cárdeno, pág. 83), e incluso, figuradas, (Spaniarsi. Metafóricamente desenredarse, desprenderse de las varetas de liga, pág. 195), aunque hay que decir que las marcas de uso son muy esporádicas en todo el Alfabeto;

5) las unidades pluriverbales, que no aparecen como entradas independientes (Stare. Rejido de otros verbos [...] Stare a bada. [...] / Stare a bada, o alla bada. [...] /Stare a banco. [...] /Stare a boca aperta. Estar [...] / Stare a boca aperta. Aguardar [...] / Stare a campo. [...] /Stare a capello. [...] / Stare a capo chino, o basso. [...] /Stare a capo algo. [...] /Stare a capo all'ingiù. [...], pág. 203).

Sin duda alguna, este Alfabeto italiano-español es la aportación novedosa más importante a la lexicografía bilingüe entre estas dos lenguas a lo largo del siglo XVIII. Se sitúa más en la tradición de lo que había sido la lexicografía bilingüe hasta Franciosini y sus posteriores ediciones que en la modernidad de la práctica lexicográfica que se inaugura en el siglo de las luces. Se convierte en heredero directo del lexicógrafo del siglo XVII tanto en la macroestructura, con el que comparte casi un $70 \%$ de las entradas, como en la constitución y redacción de la microestructura, aunque en este apartado sí que se observa una mayor sistematización y un claro intento de reducir la información a lo estrictamente lingüístico (Martínez Egido 2008b) ${ }^{57}$. Ahora bien, a pesar de lo dicho anteriormente, este Alfabeto no debe entenderse como algo anecdótico por no haber sido concebido como un

\footnotetext{
${ }^{57}$ El estudio comparativo realizado entre el Alfabeto de Terreros y el Vocabulario de Franciosini de donde se han extraído estos datos se llevó a cabo con una muestra de 288 entradas de la parte italiano-español del diccionario de Franciosini, distribuidas de la siguiente forma: 98 entradas de la letra "B", desde babbo hasta ballare; 79 entradas de la letra "L", desde la hasta lamina; y 111 entradas de la letra "T", desde tabacco hasta tarpare.
} 
verdadero diccionario bilingüe, sino que, por el contrario, debe ser estudiado detenidamente pues, por lo ya observado y analizado, puede ofrecer un gran interés para la historia de la lexicografía bilingüe española e italiana.

\section{LA LEXICOGRAFÍA BILINGÜE ESPAÑOL-ITALIANO: EL SIGLO XIX}

\subsection{Actividad lexicográfica}

En el siglo XIX, al contrario de lo ocurrido durante la centuria anterior, se asiste a un resurgimiento de la publicación de diccionarios bilingües español-italiano superior al ocurrido en los siglos XVI y XVII. Este hecho contribuye a que el diccionario de Lorenzo Franciosini, publicado doscientos años antes y con una larga vida editorial, deje de editarse para dar paso a obras nuevas que pueden satisfacer las demandas que el público necesita para el aprendizaje de ambas lenguas como lenguas extranjeras.

La producción de diccionarios bilingües español-italiano, aunque constante durante este siglo, es exigua si la comparamos con la publicación de otros diccionarios bilingües como es el caso del español y el francés (Cazorla 2005); aún así vieron la luz una serie de obras lexicográficas (Carriscondo 1999: 270-271) que cumplieron y satisficieron la demanda existente. Nos referimos a las publicadas por Cormon-Manni (1805), Scalan (1837), Martínez del Romero (1844), Rosa y Bonet (1853), Caccia (1869), Canini (1875) y Linati y Delgado $(1887)^{58}$ y a las obras lexicográficas consideradas menores, por su extensión, como fueron las nomenclaturas o pequeños diccionarios que se editaban junto a las gramáticas y a las obras de diálogos que seguían la tradición aparecida en el siglo XV (Ayala 1990) y que se va a perpetuar y a consolidar como un producto lexicográfico muy exitoso. Este desarrollo lexicográfico coincide, a la vez que contrasta en la cuantía de obras, con la producción monolingüe del español (Seco 1997; Alvar 1995; Bueno 1996; Azorín 2000, 2003b, 2004, 2007) ya que durante este siglo se publican diez nuevas ediciones del diccionario de la Real Academia Española ${ }^{59}$, a la vez que surge una amplia y extensa producción de obras lexicográficas extraacadémicas al hilo del diccionario académico que se configura, solamente durante la primera mitad del siglo, entre otras obras de menor importancia, con la edición de los diccionarios de Vicente González Arnao (1822) ${ }^{60}$, Manuel Núñez de Taboada $(1822)^{61}$, Cristóbal Pla y Torres $(1826)^{62}$, José René Massón $(1826)^{63}$, Juan Peñalver $(1842)^{64}$, Vicente Salvá $(1846)^{65}$, Castro $(1852)^{66}$, y el de la

\footnotetext{
${ }^{58}$ Las referencias bibliográficas completas las ofreceremos a continuación en la descripción de cada una de estas obras.

${ }^{59}$ Las fechas de publicación fueron: 1803, 1817, 1822, 1832, 1837, 1843, 1852, 1869, 1884 y 1899.

${ }^{60}$ Diccionario de la lengua castellana, Madrid, P. Sanz y Sanz.

${ }^{61}$ Diccionario castellano, París, Seguin.

${ }^{62}$ Diccionario de la Lengua castellana por la Academia Española, París, Cormon y Blanc.

${ }^{63}$ Diccionario de la lengua castellana, por la Academia Española, París, Masson e hijo.

${ }^{64}$ Panléxico. Diccionario Universal de la Lengua Española, Madrid, I. Arboix.
} 
Sociedad Literaria $(1853)^{67}$. Junto a todos ellos, también se publicaron diferentes diccionarios enciclopédicos ${ }^{68}$, mezcla de lo que se considera una enciclopedia y un diccionario de lengua, caracterizados por una macroestructura muy extensa con léxico no perteneciente al general de una lengua y con datos enciclopédicos no lingüísticos. Entre todos los publicados en español destacan por su importancia el de Ramón Joaquín Domínguez (1846-1847) ${ }^{69}$, autor también de una gramática y de una ortografía francesa en la línea de la tradición de los maestros de lengua, y el de la editorial Gaspar y Roig (1853$1855)^{70}$

Evidentemente, tal eclosión de obras lexicográficas con el español como lengua de trabajo debió de responder a necesidades exteriores a la propia práctica lexicográfica y que debemos buscar en la sociedad europea de la época, marcada por la dicotomía entre el sentimiento y la razón, los movimientos ideológicos en favor de los nacionalismos, el auge del pensamiento positivista y el avance en las ciencias experimentales y los nuevos cauces para la manifestación de la libertad de expresión que supuso el desarrollo del periodismo. Todos estos factores socioculturales favorecieron todavía más la preocupación y el interés por el lenguaje. Ahora bien, aunque la creación de vocabularios o diccionarios bilingües siempre ha respondido a la necesidad de aprender una lengua diferente a la propia, esta labor lexicográfica se debió también a una intención comercial que se vio reforzada según surgía un nuevo público necesitado de ella y, por tanto, potencialmente consumidor. En el siglo XIX este nuevo público se debe sobretodo al mercado emergente que supuso la emancipación de las colonias españolas de América (Seco 1997: 130) y al necesario y deseado contacto con ellas que propició la necesidad de aprender español por parte de los países de Europa occidental. En el caso de Italia, además de ese factor, debe tenerse en cuenta la emigración de los ciudadanos italianos hacia los nuevos países hispanoamericanos, sobre todo a los que configuran el cono sur del continente. Estos motivos fueron los que promovieron el interés comercial de los editores para publicar nuevas obras lexicográficas y que explicarían su aparición, en contra de la ausencia de nuevos diccionarios bilingües español-italiano durante más de cien años antes. Se comprueba, por tanto, que en el desarrollo de la práctica lexicográfica siempre van aunados los factores socioculturales y los factores económicos, es decir, la concepción del diccionario como un producto pedagógico y también comercial.

\subsection{La producción lexicográfica bilingüe español-italiano}

Para la exposición y el estudio de los diccionarios bilingües español-italiano en esta centuria se ha seguido el mismo procedimiento que en los apartados anteriores, es decir, el

\footnotetext{
${ }^{65}$ Nuevo Diccionario de la lengua castellana, París, Fournier.

${ }^{66}$ Gran Diccionario de la Lengua castellana, Madrid, Seminario Pintoresco Español y de la Ilustración.

${ }^{67}$ Nuevo Diccionario de la Lengua castellana, París, Rosa y Bouret.

${ }^{68}$ Para una descripción de las obras de este período, Azorín Fernández (2000: 234-247, 257-272).

${ }^{69}$ Diccionario Nacional o Gran Diccionario Clásico de la Lengua Española, Madrid, Bernat.

${ }^{70}$ Diccionario Enciclopédico de la Lengua Española, Madrid.
} 
orden cronológico de publicación. Ahora bien, por la idiosincrasia de todas las obras aparecidas en este siglo, al efectuar la selección de las más importantes y representativas ${ }^{71}$, se ha optado por agruparlas de acuerdo a las tres líneas de práctica lexicográfica bilingüe constatadas, a saber, los diccionarios de bolsillo destinados a su portabilidad y de ahí su pequeño tamaño y su precio reducido (Cormon y Manni 1805, Caccia 1869) ${ }^{72}$, los diccionarios extensos que no presentan las limitaciones anteriores (Martínez del Romero 1844, Linati y Delgado 1887) y los diccionarios de especialidad extensos, tanto en el número de entradas que configuran su macroestructura como en la cantidad de información que aportan en su microestructura, por la novedad que suponen en la consideración de este tipo de léxico (Scalan 1831).

En relación a la línea primera reseñada en el quehacer lexicográfico, en 1805 aparece publicado en Lyon el primer diccionario italiano-español, español-italiano de este periodo que nos ocupa, en cuya portada podemos leer:

Dizionario da tasca italiano-spagnuolo e spagnuolo-italiano, composto sul dizionario dell'Accademia Spanguola ultima ed., e sul vocabulario degli Accademi della Crusca per J.L.B.Cormon y Vicenzo Manni.

Se trata de un diccionario perteneciente a los conocidos como "de faltriquera" o "portátil" por lo pequeño de su tamaño, $14 \mathrm{~cm}$, destinados a la consulta rápida o al aprendizaje por parte de los escolares y que, debido a sus dimensiones, sería fácil su transporte ${ }^{73}$. Es aquí donde radica su verdadera naturaleza, tal y como se reconoce en el prólogo:

L'UTILITA de'Dizionarj da tasca, sarebbe un problema, se mai non avessimo la prova di fatto dello spaccio considerabile de'medesimi, e dell'acconglienza favorevole del

\footnotetext{
${ }^{71}$ Además de las obras expuestas y estudiadas en este trabajo, Felix San Vicente, en el Cliro, Instituto Lingüistico de la Universitá di Bologna, http://hesperia.cliro.unibo.it/ricerca_en/lista_anni.asp reseña las siguientes:

Anónimo (1854). Nuevo Diccionario español-italiano, italiano-español, París, Rosa y Bouret. Se reedita en cuatro ocasiones: París, 1860; Poissy, 1863, y dos más en París, 1877. Se trata de una copia del diccionario de Cormon-Manni de 1805 (Gallina 1991).

Anónimo (1854). Nuevo Diccionario italiano-español y viceversa, Gerona, Grases.

Società di Professori (1868). Dizionario italiano-spagnolo, spagnolo-italiano, Milán, P. Carrara.

Anónimo (1873). Nuevo diccionario italiano-español y español-italiano, Milán, Ferrario. Se reedita en tres ocasiones más (Milán, 1875; Guigoni, 1890 y 1898). Según Gallina (1991) se basa en el anónimo de 1853 y en el diccionario de Caccia de 1869.

M. A. Canini (1875). Diccionario español-italiano-español, Milán / Nápoles, F. Pagnoni. Es el primer diccionario bilingüe español-italiano publicado en Italia en el siglo XIX y es una mezcla del Nuevo diccionario de 1853 y del de Caccia (1869) sin aportaciones originales (Gallina 1991). Es reeditado en Milán (1883).

B. Melzi, C. Boselli (1893). Nuovo Dizionario spagnolo-italiano e italiano-spagnolo, Milán, Fratelli Trevers, 2 vols. Reeditado en Milán (1894).

${ }^{72}$ Las referencias bibliográficas completas de los diccionarios consignados en este párrafo se ofrecerán posteriormente en el análisis de cada uno de ellos.

${ }^{73}$ En la edición de 1821 se le suprime del título la referencia a su tamaño para comercializarlo como un diccionario general de formato medio.
} 
publico. Siffatta riuscita non tanto alla natura della composizione, quanto al comodo della forma de libro, ed alla viltà del prezzo senza dubbio è dovuta. (Pág. I) ${ }^{74}$

Está dividido en dos partes, como índica su título. La primera de ellas va encabezada por un listado de Conjugaciones de los verbos regulares e irregulares que abarca las primeras once páginas con numeración romana. La página siguiente la ocupa una Explicación de las señales y abreviaturas usadas en este tomo. A continuación se desarrolla el cuerpo del diccionario que ocupa 369 páginas a triple columna. Consta de unas 35.400 entradas $^{75}$, cuya principal característica es que aparecen lematizadas; palabra esta que, evidentemente, los autores no utilizan en el prólogo pero sí que aluden a que su método de proceder se debe al intento de favorecer la consulta del diccionario por parte de sus usuarios y, también, a elementos prácticos inherentes a su comercialización, como son la extensión del diccionario y el precio que puede alcanzar en la librería ${ }^{76}$. Esta práctica, si bien no es nueva en la actividad lexicográfica monolingüe ${ }^{77}$, sí lo es en la tradición bilingüe español-italiano, como se ha ido viendo en este estudio, pues ya queda muy lejos en el tiempo la forma de construir la macroestructura de Franciosini. Los mismos editores indican en el prólogo cómo han construido el cuerpo de sus entradas y cómo aparecen las diferentes acepciones de una palabra agrupadas bajo el mismo lema: "Per la facilità del lettore, abbiamo separato con questo segno + i varj significati della stessa voce". Un ejemplo de artículo que sigue esta construcción con ocho acepciones diferentes, según los lexicógrafos, sería:

Avisare, va. Advertir, reparar + ver, mirar + imaginar + instruir + vn. Pensar, ser de parecer, + vr. Reflexionar, imaginarse + prepararse à ... + pelear. (Pág. 36)

La construcción del artículo lexicográfico en este diccionario, además de la novedad que supone la agrupación de los significados, es decir, las diferentes acepciones, bajo una misma entrada, hecho que marcará una tendencia en los diccionarios bilingües españolitaliano en esta centuria, se caracteriza también por la aportación de la categoría gramatical de las entradas mediante abreviaturas y por la concisión en la redacción de la microestructura, bien mediante la traducción directa (Avvertenza, sf. Advertencia, reparo,

\footnotetext{
${ }^{74}$ La edición que se utiliza en este trabajo es la de 1845 existente en la Biblioteca Nacional bajo la signatura 1/31637, cuya portada reza: DICCIONARIO / ITALIANO-ESPAÑOL / Y ESPAÑOL-ITALIANO / COMPUESTO Y FIELMENTE RECOPILADO SEGUN LA ULTIMA EDICIÓN DEL DICCIONARIO DE LA ACADEMIA ESPAÑLLA, Y EL VOCABULARIO / DE LA ACADEMIA DE LA CRUSCA / POR / CORMON Y MANNI; / Nueva edición revista y aumentada / POR S. H. BLANC. / LYON / LIBRERIA CORMON Y BLANC, VIA ROGER, N. 1 / 1845 .

${ }^{75}$ El número total de entradas de esta primera parte se ha extraído ponderando la media de entradas por página tras un muestreo representativo de 12 páginas aleatorias del diccionario. El cómputo de las entradas ha sido (señalamos en primer lugar el número de la página y en segundo lugar el número de entradas de la página): 56: 77; $57: 88 ; 58$ : 93; 59: 99; 176: 112; 177: 109; 178: 111; 179: 103; 340: 79; 341: 98; 342: 96; 343: 89.

${ }^{76}$ Según se dice en la primera página del prólogo: “[...]ed alla viltà del prezzo senza dubbio è dovuta. [...] l'autor d'un Dizionario da tasca non potendo far un uso frequente delle definizioni sminuzzolate, degli esempj, e di tutti i mezzi impiegati da'lessicografi $[\ldots]$ ”.

${ }^{77}$ En la primera parte del prólogo, los editores apuntan cuáles han sido sus referentes y sus fuentes directas: “Gli elementi dell'opera son cavati dall'ultima edizione del Dizionario dell'accademia Spagnuola, e dal vocabolario degli accademici della Crusca".
} 
pág. 36; Lanciatore, sm. Lanzador, pág. 178); bien mediante una brevísima definición cuando la traducción directa no es posible (Barberare, vn. Girar como el peon, pág. 39; Svoltamento, sm. La acción de destorcer, pág. 340), o también, aunque menos numerosas, mediante la combinación de ambas (Lagrimazione, sf. Llanto, derramamiento continuo de lágrimas, pág. 177). Esta concisión en la construcción de la microestructura condiciona la práctica ausencia de unidades fraseológicas en ella, aunque sí aparecen algunos casos de colocaciones como por ejemplo: Svernamento, sm. Invernada, + (invernada) d'uccelli, gorgeo de los pajaritos, al salir del invierno (pág. 340).

Estas mismas características (Gallina 1991: 2993), tanto macroestructurales como microestructurales, se observan en la construcción de la segunda parte del diccionario, español-italiano, condicionada también por el diseño motivado por construir un diccionario de bolsillo con un conjunto de entradas aparentemente tan elevado para esta clase de obras. Se inicia esta segunda parte con una Coniugazcioni de'verbi regolari, ed irregolari que abarca nueve páginas numeradas con caracteres romanos, para dar paso al diccionario que ocupa 324 páginas numeradas en arábigo también a tres columnas. El número de entradas consignado es algo inferior al de la primera pues alcanza un total de $32.200^{78}$. Las diferentes acepciones de una palabra, tal y como ya se ha apuntado, aparecen incluidas en la microestructura como se puede observar en los siguientes ejemplos:

Bajo, ja. A. basso + de ley, di bassa lega + sm. Basso, in musica $+V$. Bajio + unghia del cavallo + pl. vesti, sottane di donna + piedi del cavallo + av. Sotto vocce + V. Abajo, Debajo + por lo bajo, segretamente + bajo mano, sotto mano. (Pág. 52)

Tejo, sm. Pezzo di tegola + giuoco delle piastrelle + tavola tonda di metallo + pezzo d'oro in massa + tasso, albero. (Pág. 297)

También se siguen los tres procedimientos ya consignados para la redacción del artículo lexicográfico: dar la equivalencia de la entrada mediante la traducción directa (Juzgar, va. e n. giudicare, pág. 202); definición perifrástica cuando no es posible lo anterior (Tafiletear, va. fregiar di marrocchino, pág. 295; Tabaqueria, sf. officina di tabacco, pág. 294; o la combinación de ambas (Tahueria, sf. bisca + bareria al giuoco, pág. 295; Bañador, ra, s. bagnaiulo + specie di tinello, pág. 53). La diferencia de esta segunda parte respecto a la primera estaría en que aquí se introducen de forma algo más abundante, pero muy tímidamente, diferentes unidades fraseológicas y colocaciones, como por ejemplo: Bajar, va. [...] bajarse de la querella, desistere dalla querela, pág. 51; Tañido, sm. [...] + tañido di campana, pág. 296; o en el artículo Bajo, constatado anteriormente. Esta pequeña diferencia en este aspecto puede deberse a la utilización de las fuentes, es decir, a la influencia del diccionario de Franciosini más concretamente, ya que este lexicógrafo para la elaboración de la parte español-italiano se basó en el Tesoro de Covarrubias (Martínez Egido 2003) de donde extrajo la mayor parte de las unidades fraseológicas que incluyó en su obra, como ya se explicó. Pero, de todas formas, se aleja mucho en este aspecto de su

\footnotetext{
${ }^{78}$ El número total de entradas de esta segunda parte se ha extraído ponderando la media de entradas por página tras un muestreo representativo de 10 páginas aleatorias del diccionario. El cómputo de las entradas ha sido (señalamos en primer lugar el número de la página y en segundo lugar el número de entradas de la página): 50: 92; 51: 97; 52: 92; 53: 81; 202: 117; 203: 113; 294: 102; 295: 93; 296: 96; 297: 112.
} 
fuente, pues en voces como dar, echar, saber o sacar, no incluye ninguna unidad de este tipo cuando en Franciosini son muy abundantes.

De esta forma, por todo lo analizado y expuesto, el diccionario de 1805 de Cormon y Manni, supuso un avance positivo en la concepción del diccionario bilingüe españolitaliano respecto a la labor en esta tradición lexicográfica, sobre todo en la construcción lematizada de la macroestructura y en la redacción sucinta del artículo lexicográfico. Bien es cierto que, aunque el Vocabulario de Lorenzo Franciosini no se publicara más, el diccionario de Cormon y Manni, por los condicionamientos que supone el ser una obra de bolsillo, todavía no pudo superar ni el valor lexicográfico ni la verdadera riqueza y utilidad del diccionario del lexicógrafo del siglo XVII, aunque obtuvo un gran éxito de ventas, corroborado por las siete reediciones ${ }^{79}$ que se produjeron durante los dos primeros tercios del siglo XIX.

Durante 64 años la obra de Cormon y Manni fue el diccionario español-italiano por excelencia, hasta que llegó su declive con la publicación del diccionario de José Caccia en 1869. Este diccionario también catalogado como de bolsillo sigue la misma estructura y se encuentra dividido en dos partes. En la portada de la primera de ellas puede leerse:

NUEVO DICCIONARIO / ITALIANO-ESPAÑOL / CON / LA PRONUNCIACIÓN FIGURADA EN AMBAS LENGUAS / COMPUESTO / SOBRE LOS MEJORES TEXTOS CONTEMPORÁNEOS / ITALIANOS Y ESPAÑOLES / POR / JOSÉ CACCIA / NUEVA EDICION / PARIS / LIBRERIA DE GARNIER HERMANOS / CALLE DES SAINTS-PÈRES, $6 . / 1869 .^{80}$

Comienza con un prefacio de 2 páginas en el que se hace eco de que, en muchas ocasiones, las obras lexicográficas son meras copias de las anteriores ("Moli sono i libri di siffattol genere che videro la luce per le stampe; ma i più non offrono che ripetizioni e copie servili de altri dizionari dai quali non differiscono che per poche aggiunte o soppressioni, senza punto colmare le lacune che in quelli si notano", pág. I), mientras que el autor, en palabras de su editor, "a reunire elementi numerosi e scelti per un lavoro più utile dei precedenti”, como son los términos técnicos y científicos y los neologismos surgidos por la necesitad de la lectura de los periódicos y de la obras modernas (pág. I). También da noticia de que incluye la pronunciación figurada en cada una de las lenguas para "supplire all'insegnamento orale che esige ogni lingua straniera" (pág. II). Por último, incide en el

\footnotetext{
79 Las siete reediciones, constatadas en Cliro, Centro Lingüistico Universitá di Bologna (http://hesperia.cliro.unibo.it/ricerca en/lista anni.asp) fueron: 1821, Lyon, Cormon y Blanc; 1833, Madrid, Tomás Jordán; 1838, París, Cormon y Blanc; 1843, Lyon, Cormon y Blanc; 1848, Lyon-París, Cormon y Blanc; 1854, Lyon-París, SH Blanc y C.; 1865, Lyon-París, N. Scheuring: Cormon y Blanc.

${ }^{80}$ No se ha podido acceder a esta primera edición, aunque en la Biblioteca Nacional de Madrid existen dos ejemplares bajo las signaturas 4/123814 y 1/123814, en el momento de la consulta eran inaccesibles. En este estudio se ha utilizado la edición de 1874 que se encuentra en la Biblioteca Nacional de Madrid bajo la signatura 4/180580. Felix San Vicente no se hace eco de esta edición por nosotros consultada y nombra una reedición de 1901, que se encuentra en la Biblioteca de la Universidad de Deusto en Bilbao. Describe que se trata de una reimpresión ya que coincide en el número de páginas de cada parte, así como en la distribución de ellas. Esta coincidencia se extiende también al ejemplar de 1874 manejado en este estudio. La única diferencia entre la portada de 1869 y la manejada por nosotros es la inclusión, tras el nombre del autor, de las palabras NUEVA EDICIÓN.
} 
tratamiento tipográfico de las entradas para facilitar la labor del usuario. Corresponde todo ello un preámbulo habitual de diccionario, es decir, el alabar la labor realizada y el presentarse como bueno y útil.

Continúa el diccionario con las CONJUGACIONES DE LOS VERBOS REGULARES É IRREGULARES, que ocupan 8 páginas. En la página siguiente se consigna una tabla de las abreviaturas que han sido utilizadas a lo largo de la obra y que consta de un total de 54 marcas listadas alfabéticamente pero que, una vez analizadas, podrían ser agrupadas en cuatro grupos diferenciados: el primero se compondría de 16 abreviaturas que recogerían las marcas gramaticales de las entradas ( $A . ; A d j ., A d v, F$., Imper., ...); el segundo, el más numeroso con 32 abreviaturas, serían las marcas técnicas y profesionales (Agr., Anat., Arit., Arqu., Impr., Com., ...); el tercero, con 5 abreviaturas, recoge las marcas de uso (Fam., Met., Pop. Ret. y Vulg.); y, por último, una marca referida a la utilización del diccionario $(V .$, Véase). Lo importante de esta información es que es la primera vez que aparece en un diccionario bilingüe italiano-español una relación de marcas referidas al ámbito técnico y profesional, por lo que recoge lo que ya era habitual en el campo de la lexicografía monolingüe y, más específicamente, en los diccionarios propiamente técnicos referidos a alguna especialidad, como sería el caso de la obra de Scalan, que se describirá después.

Estas nueve páginas iniciales aparecen con numeración romana. A continuación comienza el diccionario que abarca 528 páginas numeradas en arábigo, en las que la información se expone a dos columnas y recoge 39.600 entradas ${ }^{81}$, destacadas tipográficamente al estar en negrita y, como viene siendo habitual en estas obras, facilitar la labor de consulta del diccionario. La lematización es sistemática a lo largo de la obra pues, bajo una misma entrada, incluye toda la información que ofrece. Este hecho ya será una constante en la tradición bilingüe español-italiano, pues se adopta como principio formal en la construcción del diccionario.

La redacción de la microestructura ofrece la novedad de que, en algunos artículos en los que la grafía italiana no se corresponde con la pronunciación de la grafía española, incluye la pronunciación de la lengua de entrada mediante una adaptación gráfica, bastante rudimentaria, a la lengua de salida para que el usuario conozca cómo debe pronunciarse o "sonar". Ejemplos de ello serían: Avvignare a. avviñare. [...], pág. 50"2; Avvincere. Avvinchere. [...], pág. 50; Ballare n. bal-lare [...], pág. 54; Tachigrafia $f$. taquigrafia [...], pág. 485. El resto de la información que ofrece se articula en un orden sistemático: en primer lugar la caracterización gramatical y, a continuación, procura la equivalencia y, en algunos casos, algún sinónimo de ella (Balista $f$. Ballesta, pág. 54; Balzante adj. Salton, retozon, pág.; en ocasiones, ofrece una definición perifrástica cuando no es posible la equivalencia (Barbareggiare $n$. Hacer barbarismos, pág. 55); o, la combinación de varias

\footnotetext{
${ }^{81}$ El número total de entradas de esta primera parte se ha extraído ponderando la media de entradas por página tras un muestreo representativo de 13 páginas aleatorias del diccionario. El cómputo de las entradas ha sido (señalamos en primer lugar el número de la página y en segundo lugar el número de entradas de la página): 50: 69; 51: 67; 52: 67; 53: 84; 54: 78; 55: 86; 252: 50; 253: 88; 484: 78; 485: 70; 486: 80; 487: 93; 528: 62 .

${ }^{82}$ El número de las páginas consignado en los ejemplos que se muestran corresponde a la edición que se ha consultado, 1874 .
} 
de estas posibilidades con la definición, la equivalencia y alguna otra acepción (Banca $f$. Banco en que se deposita dinero ganando interés. // Banca, giro o comercio de banca. // Banco, banqueta, pág. 54); o también, en muy pocos casos y muy poco abundante cuando aparece, alguna expresión pluriverbal (Tagliare a tallare. Cortar. // Poner talla. // Separar. // Engañar.// _ il giubbone, murmurar. // _ le parole in bocca, interrumpir. // si. R. Cruzarse, pág. 485).

La segunda parte, NUOVO DIZIONARIO ITALIANO-SPAGNUOLO E SPAGNUOLO-ITALIANO, contiene en su portada los mismos datos pero traducidos al italiano que se han consignado en la primera parte. También comienza con un PREFACIONE de dos páginas, una CONIUGAZIONI DE'VERBI REGOLARI, ED IRREGOLARI que abarca ocho páginas, seguida de otra dedicada a las ABBREVIATURE, todas ellas con numeración romana. El diccionario consta de 333 páginas, con numeración arábiga, con la información distribuida en dos columnas como en la primera parte y con un total de 27.000 entradas ${ }^{83}$ bien lematizadas también, número significativamente inferior al constatado en la primera parte italiano-español.

Tanto la redacción como la información incluida en la microestructura siguen los mismos patrones que en la primera parte. Ofrece la pronunciación en español para los usuarios italianos en los casos en que la grafía no se corresponda con el sonido (Languidez f. langhidez. Languidezza, pág. 230); para continuar con una única equivalencia (Laud m. Liuto, pág. 231) o varias, mediante la adición de sinónimos (Juzgar, a. juzgar. Giudicare. // n. Giudicare, immaginare, congetturare, pág. 229), o con una definición perifrástica de la entrada (Azogadamente avv. Azogadamente. Con prestezza ed agitazione, pág. 60) y, solo en casos muy concretos incluye algún tipo de marca (Tamisa f. tamissa. // geogr. Tamigi, pág. 309). Aunque en la primera parte había alguna expresión pluriverbal, en esta segunda parte no se observa que haya incluido ninguna, pues las dos constatadas en la muestra que manejamos aparecen como entradas de la macroestructura alfabetizadas por la palabra base del compuesto: Babia (estar en) loc. Essere distratto (pág. 61), Babilonia (es una) loc. Fam. É una vera Babilonia, una confusione generale (pág. 61).

Con la descripción y estudio realizado, se puede concluir que el diccionario de José Caccia no presenta ninguna novedad importante respecto a los diccionarios publicados en la primera mitad del siglo XIX. Se limita a sistematizar mejor la información que va a ofrecer en la microestructura pero limitándola en exceso, quizá debido a su condición de obra de bolsillo. Ahora, es cierto que, como ya se ha apuntado, después de su publicación el diccionario de Cormon y Manni ya no fue reeditado, por lo que la obra de José Caccia pasó a convertirse en el diccionario italiano-español de consulta y venta más importante, a juzgar

\footnotetext{
${ }^{83}$ El número total de entradas de esta segunda parte se ha extraído ponderando la media de entradas por página tras un muestreo representativo de 10 páginas aleatorias del diccionario. El cómputo de las entradas ha sido (señalamos en primer lugar el número de la página y en segundo lugar el número de entradas de la página): 60: 79; 61: 72;62: 74; 63: 72; 228: 92; 229: 66; 230: 90; 231: 99; 308: 75; 309: 88 .
} 
por las cinco reedicionesque tuvo hasta $1900^{84}$, fecha en la que se publicó el diccionario de bolsillo de Carlo Boselli ${ }^{85}$.

Junto a las obras catalogadas como de bolsillo, en esta centuria también se publicaron otros diccionarios que se intentaban alejar de esa concepción y trataban de integrar en sus páginas el mayor número de voces posible de una lengua. Son los llamados diccionarios extensos, cuyo primer representante en el siglo XIX fue la obra de Martínez del Romero, publicada en 1844. En su portada se lee:

DIZIONARIO / ITALIANO-SPAGNUOLO E SPAGNUOLO-ITALIANO / COMPILATO / DA MARTINEZ DEL ROMERO, / Membro di molte società letterarie ed artis- / tiche nazionali e satranere. / TOMO PRIMO / ITALIANO-SPAGNUOLO / MADRID / Impresso nella tipografia del Editore proprietario / SON IGNAZIO BOIX / Strada de Pontejos, n. 8. $1844 .^{86}$

El diccionario comienza con un DISCORSO PRELIMINARE que ocupa las cinco primeras páginas con numeración romana. A diferencia de lo que se incluye en este tipo de textos, Martínez del Romero, no hace ninguna observación al lector sobre las características formales de su diccionario, es decir, sobre la práctica lexicográfica que se ha ejercido en él. Sin embargo justifica y constata diversos aspectos como el cambio lingüístico que ocurre en las lenguas ("Come girano i secoli e mutano le nazioni, si modificano i costumi, nascono ed avanzano le arti, si estende il commercio e la industria, spuntano nuove invenzioni; cosí il linguaggio si muta [...]", pág. VI) ${ }^{87}$; la necesidad de aprender nuevas lenguas como consecuencia de la evolución social ("Onde facilitare i mezzi di apprendere differenti idiomi, cominciarono a compilarsi da remoti tempi grammatiche e dizionarj, [...]”, pág. VI); las numerosas fuentes consultadas que abarcan diccionarios y gramáticas anteriores así como los autores literarios clásicos y modernos, en español y en italiano, que han escrito en alguna de estas dos lenguas y, por último, también los términos técnicos (di arti, mestieri, navigazione, commercio, guerra, págs. IX-X).

A continuación presenta en 25 páginas una CONJUGAZIONI / de'verbi tanto regolari che irregolari. Para ya comenzar el diccionario que abarca un total de 1151 páginas, hasta la letra $I^{88}$, en las que la información se recoge en dos columnas. El número de entradas de

\footnotetext{
84 Las cinco reediciones, constatadas en el Cliro, Centro Lingüistico Universitá di Bologna (http://hesperia.cliro.unibo.it/ricerca_en/lista_anni.asp) fueron: 1874, 1882, 1887, 1889 y 1895, todas ellas publicadas en París, Garnier.

${ }^{85}$ C. Boselli (1900). Nuovo dizionario tascabile spagnuolo-italiano e italiano-sapagnuolo, Milán, Fratelli Treves.

${ }^{86}$ En los ficheros de la Biblioteca Nacional de Madrid sólo consta este ejemplar del tomo I que hemos reseñado, por lo que el diccionario aparece incompleto. En la relación que ofrece Felix San Vicente en Hesperia tampoco se consigna nada relativo al segundo tomo http://hesperia.cliro.unibo.it/ricerca en/ricerca scheda.asp?idRecord=197 La signatura de la BN del ejemplar estudiado es 5/3667, aunque hay dos ejemplares idénticos del mismo tomo con diferentes signaturas.

${ }^{87}$ Todos los ejemplos que se citen de esta obra corresponden a las páginas de la edición que se ha descrito en este trabajo.

${ }^{88}$ Todos los datos que se ofrecen en este estudio referentes a este diccionario sólo abarcan lo contenido de este primer tomo.
} 
esta parte alcanzaría las $48.700^{89}$, de lo que se deduce que sería ya un diccionario bilingüe muy amplio y extenso en cuanto a la macroestructura se refiere. Ésta se presenta lematizada y visualmente destacada al haberse impreso en mayúsculas.

La redacción de los artículos lexicográficos no es uniforme, pues éstos presentan diferente extensión según la cantidad de información que el lexicógrafo considera adecuada o conoce, sin un plan previo de actuación. Un ejemplo de ello sería la construcción del artículo lexicográfico $B A B B A C C I O, B A B B A C C I O N E$, donde ofrece 51 supuestos sinónimos y lo acaba con una apreciación personal:

BABBACCIO, BABBACCIONE, m. Bobo, bobalicon, lerdo, estúpido, fátuo, torpe, bausan, tonto, tonton, memo, bodoque, papamoscas, papanatas, zoquete, porro, toronco, leño, pelele, rudo, necio, mándria, sinple, sinplon, sinplazo, sinplonazo, pendejo, calandrajo, modrego, bolo, molondron, mastuerzo, zonzo, zolocho, zamacuco, gaznápiro, zamarro, mentecato, záfio, zopenco, zanbonbo, babieca, badulaque, monigote, vainazas, babazorro, pánfilo, ganbalúa, banbárria, mamacallos, majadero, sandio, i algun otro que no recuerdo. (Pág. 176)

Además de anotar en todas las entradas su categoría gramatical mediante una abreviatura, como ya se ha visto en obras anteriores, también aporta informaciones añadidas mediante la asignación de marcas, tanto de uso (BACATO, TA, p. p. de Bacare. [...] fig. Algo enfermo, malo un poco indispuesto, pág. 177), como técnicas (BACINO, anat. La pelvis,- naut. Concha de un puerto; [...], pág. 179).

El tipo de información léxica que brinda también varía, pues aunque hay una clara tendencia a la expansión del artículo, puede ofrecer en español simplemente uno o varios sinónimos (BACOLINO, m. dim. Gusanillo, pág. 180), (BACUCCO, m. Capucha, capilla, capuz, capuchon, pág. 180), o el ejemplo anterior de los 51 sinónimos; una definición de la entrada (BAGGIOLARE, v. a. Apoyar ó colocar un trozo de piedra sobre unos cilindros de madera ó zoquetes para sostenerle i poderle labrar i mover, pág. 181); o una definición perifrástica (BALAUSTRATO, TA, a. arq. Que está adornado con balaustres, pág. 184). Aunque lo más habitual en este diccionario es que toda esta casuística aparezca mezclada en la redacción de los artículos junto a una abundante constatación de unidades pluriverbales, como puede ser el siguiente ejemplo en el que se ofrece la traducción directa, sinónimos de ella en español, definiciones léxicas y perifrásticas, marca de uso figurado y una unidad pluriverbal con su explicación:

BALBETTARE, v. n. Tartamudear, balbucir; tartajear, tartalear.- Pronunciar mal, ablar balbuciendo, con dificultad por inpedimento de la lengua. fig. Ablar sobre un objeto confusamente i sin el debido conocimiento.- Dícese que una lingua balbetta bambina, para significar que comienza á formarse i que aun no es perfecta. (Pág. 184)

Incluso en la forma de incluir las diferentes acepciones de las entradas también se observan variaciones pues, o bien lo realiza tal y como hemos visto en los ejemplos

\footnotetext{
${ }^{89}$ El número total de entradas de esta parte se ha extraído ponderando la media de entradas por página tras un muestreo representativo de 10 páginas del diccionario. El cómputo de las entradas ha sido (señalamos en primer lugar el número de la página y en segundo lugar el número de entradas de la página): 176: 29; 177: 39; 178: 32; 179: $38 ; 180: 27 ; 181: 44 ; 182: 27 ; 183: 48 ; 184: 40 ; 185: 28 ; 186: 35 ; 187: 36$.
} 
anteriores, o bien presenta diferentes subentradas marcadas gráficamente, como se puede ver en el siguiente ejemplo en el que utiliza dos entradas diferenciadas para la palabra bagno y, en la primera de ellas, tres subentradas con diferente tipografía y, a su vez, diferentes acepciones y unidades pluriverbales en algunas de ellas:

BAGNO, m. La accion de bañar i bañarse.- Baño: inmersión del cuerpo en el agua, sea en el mar, en el rio, etc.

- Baño: el estanque, cuba ó utensilio con agua en que se toma el baño.

BAGNI, pl. Baños: las aguas medicinales, que toman la denominación del pueblo ó paraje donde se hallan.- I bagni, di Carratraca, di Ardales, di Sacedon, di Trillo, los baños de Carrtraca, Ardales, etc.

BAGNI. Baños. Los parajes ó sitios á propósito de un rio ó del mar dispuestos para poderse bañar; bañadero. - BAGNO MARIA, f. farm. Baño maría: agua hirviendo en que se mete algun vaso á fin de que no esté en contacto con el fuego. - Bagno seco, baño de arena, sirve para los mismo que el baño maría. - pl. ant. BAGNORA.

BAGNO, m. Baño: nombre de la mazmorra en que estan los esclavos en Berbería i Turquia. Dícese lo mismo del sitio donde está la chusma de los condenados á galeras por varios delitos.- Cuartel de presidio.

En definitiva, puede afirmarse que el Diccionario italiano-español de Martínez del Romero todavía carece de un diseño o planta regular en la redacción del artículo lexicográfico. Indudablemente, es cierto que la voluntad de su autor fue la de dotar al alumno extranjero que deseara o necesitara aprender una de estas dos lenguas, de un instrumento, su diccionario, que le facilitara la labor. Pero no tuvo éxito ya que, si bien intenta adoptar los criterios modernos lexicográficos ya imperantes en la lexicografía monolingüe del español, como puede ser lo concerniente a la selección y a la construcción de la macroestructura o a la inclusión de marcas en la microestructura, todavía sigue anclado en la práctica lexicográfica del siglo XVII, en la que la normativa en la redacción del artículo lexicográfico parecía derivarse de lo que cada entrada podía albergar o sugerir al lexicógrafo. Por ello, puede explicarse la ausencia de ediciones posteriores de la obra y, consecuentemente, el poco éxito editorial que pudo tener pues no hemos podido constatar ninguna edición más fuera de la que hemos descrito y analizado.

En la estela de los diccionarios extensos, casi al final de la centuria aparece en 1887, publicado en Barcelona, el Nuevo Dizionario de Linati-Delgado que culminará la labor lexicográfica de todo este periodo de la tradición lexicográfica bilingüe español-italiano (Martínez Egido 2009), aunque, bien es cierto, que no anuló la posibilidad de publicación y de éxito editorial del diccionario de José Caccia al ser ambos productos bien diferenciados, uno considerado de bolsillo, por lo tanto muy útil y práctico para la enseñanza a los escolares y, el otro, un diccionario extenso para un público más reducido y, quizá, exigente.

La obra de Linati-Delgado consta de dos volúmenes, como es habitual en este tipo de obras, uno para la parte italiano-español y el otro para la de español-italiano. Las portadas de ambos son:

NUOVO DIZIONARIO / SPAGNUOLO-ITALIANO / compilato da / Filippo LinatiDelgado / sopra i Dizionari della Crusca o dell'Academia spagnuola, colla scorta dei 
migliori / testi contemporanei sapgnuoli / ed italiani, il più cinoketi du tutti i Dizionari finora pubblicati. / BARCELONA / STABILIMENTO TIPOGRAFICO DEI SUCCESSORI DI N. RAMIREZ E COMPAGNI / Vicolo di Escudillers, num. 4 / 1887.

NUEVO DICCIONARIO / ITALIANO-ESPAÑOL / EL MÁS EXACTO, CORRECTO Y COMPLETO DE TODOS LOS PUBLICADOS HASTA EL DÍA. / redactado en vista de los Diccionarios de la Academia de la lengua española, / del de la italiana de la Crusca, / y de los mejores textos contemporáneos italianos y españoles. / Por / D. Felipe Linati y Delgado. / BARCELONA. / ESTABLECIMIENTO TIPOGRÁFICO DE LOS SUCESORES DE N. RAMIREZ Y COMPAÑÍA. / Pasaje de Escudillers, núm. 4 / 1887.

A continuación, en cada una de las dos partes, se presenta un prólogo breve, de tres páginas, idéntico en las dos volúmenes salvo en la lengua en la que está redactado (spagnuolo-italiano en español, italiano-espagnuolo en italiano). En él, el lexicógrafo señala la inexistencia en su época de un diccionario extenso italiano-español, español-italiano, mientras que, por el contrario, tanto el español como el italiano ya lo poseen con otras lenguas europeas. Hace referencia al diccionario portátil de Cormon publicado en 1805 para subrayar la falta de un diccionario como el que él presenta. Justifica la necesidad de este diccionario apelando a las muchas y frecuentes relaciones entre España e Italia de su época: "Il defeto di un buo Dizionario italiano-spagnuolo riesce piu sensibili per essere numerose e frequenti le relazioni tra Sapagan e Italia e tra questa e l'America Meridionale ov'è in uso la lingua spagnuola" (pág. 1). Avanzando en el prólogo, refiriéndose a su propio diccionario nos dirá que "comprende non solo le voci comuni di uso frequente, ma quello eziandio che appartngono alle arti, scienze e commercio, facendole seguire da apposite abbreviature" (pág. 2). Responde así a la característica de la Europa del momento en la que, por la filosofía positivista imperante, las ciencias se alzan como el gran saber del momento. También expone que no todas las palabras tienen una correspondencia exacta en la otra lengua, por lo que se tendrán que definir, y afirma que se recogerán los significados figurados, tanto de las palabras como de las frases, proverbios y refranes, ya que en ellos las palabras pueden adquirir un significado diferente. Con esta última manifestación, Linati balbucea los conceptos, que se desarrollarán a finales del siglo XX, de fijación (Corpas 1997) e idiomaticidad (González Rey 1998) para definir las unidades fraseológicas. La diferencia respecto a las obras anteriores es que es cierto que, en gran medida, el autor cumplirá con lo anunciado en su prólogo, al contrario de lo que sucedía con los prólogos de muchas obras anteriores en los que, simplemente, se intentaba convencer al comprador.

El conjunto de su macroestructura se ve aumentado tanto por la recogida de voces que pueden haber pertenecido a otra época, como por la inclusión de "diminutivos, aumentativos y adverbios, cuya raíz y base es la voz primitiva” (pág. 3), por considerarlos necesarios para el usuario. En este mismo sentido reconoce las posibles críticas que pudiera tener el diccionario por la inclusión de voces inútiles aparentemente pero que, en absoluto, lo son. A continuación reconoce que sus fuentes directas son los diccionarios académicos españoles e italianos. Y termina el prólogo con unas consideraciones formales sobre la edición como, por ejemplo, el que la letra de los artículos sea minúscula y compacta para así abaratar los costes. Como se puede apreciar, en este tipo de publicaciones siempre está presente la característica comercial de las obras lexicográficas. 
Entre el prólogo y el cuerpo del diccionario, en cada una de sus partes, se incluyen dos páginas que recogen la Tavola delle abbreviature en la parte español-italiano y la Explicación de las abreviaturas usadas en este diccionario en la parte italiano-español. No hay una correspondencia exacta entre ambas tablas, ya que en la primera aparecen reseñadas 69 abreviaturas mientras que en la parte italiano-español son 74. Una vez analizadas todas ellas, se observa que no existe ningún denominador común que explique esta no correspondencia, ya que en la parte español-italiano hay tres que no se consignan en la otra parte ( $r$ : reciproco; Ret.: retorica; $V .:$ vedi) y faltan seis que sí que se recogen en el diccionario italiano-español (Min.: Mineralogía; pas.: pasivo; poc. us.: poco usado; refr.: refrán; sinc.: sincope; vulg.: vulgar). Todas las abreviaturas se corresponden con marcas que el lexicógrafo introduce en los artículos del diccionario y que hemos podido concentrar en tres grandes grupos: marcas gramaticales: se corresponden con la categoría gramatical de la palabra (s.: sustantivo; adj.: adjetivo; agg.: aggettivo; etc.) y alguna subcategoría gramatical (adv. de l.: adverbio de lugar; avv. L.: avverbio di luogo); marcas diastráticas: reseñan la procedencia profesional de la palabra (Agr.: agricultura; Arit.: Aritmética; Bot.: Botánica; Giur.: Giurisprudenza; etc.). Atenderían a lo señalado en el prólogo sobre la necesidad de la presencia de los posibles tecnicismos incorporados en el diccionario. Y, por último, marcas diafásicas: señalan el uso de la palabra (ant. Anticuado; vulg. Vulgar; fam.: familiar; fig. figurado; etc.). La distribución de las marcas que integran estos grupos se reparten casi equitativamente entre las dos partes del diccionario de la siguiente forma: español-italiano: 38 gramaticales, 31 profesionales y 5 diafásicas; italiano-español: 34 gramaticales, 31 profesionales y 3 diafásicas.

Tras estos preliminares comienza el diccionario en cada una de sus partes. La relativa a la ordenación italiano-español se desarrolla a través de 611 páginas, y la parte españolitaliano en 677 páginas, las cuales se ven seguidas de tres páginas más que contienen una $\mathrm{Fe}$ de Erratas. Con estos datos, si contamos las entradas medias que recoge cada una de las páginas, podríamos decir que la cantidad de entradas es muy elevada, ya que la parte italiano-español contendría más de 41.600 entradas $^{90}$ y la parte español-italiano pasaría de las 47.300 entradas $^{91}$. La lematización que presentan las macroestructuras es correcta, pues es sistemática como la ya observada en la obra de Caccia. Se presenta en letras mayúsculas frente a la minúscula utilizada en la microestructura para favorecer su consulta. Evidentemente, todo este tipo de cuestiones formales están perfectamente asumidas por los editores con el fin de acrecentar las ventas. Este incremento de las entradas se debe sobre todo a una buena utilización de las fuentes que el propio autor reconoce en el prólogo y a no tener una exigencia estrictamente funcional como ocurría con los autores de diccionarios llamados de bolsillo.

\footnotetext{
${ }^{90}$ El número total de entradas de esta primera parte se ha extraído ponderando la media de entradas por página tras un muestreo representativo de 12 páginas aleatorias del diccionario. El cómputo de las entradas ha sido (señalamos en primer lugar el número de la página y en segundo lugar el número de entradas de la página): $2: 53 ; 3: 56 ; 4: 56$; 5: 70; 7: 62; 9: 66; 40: 74; 41: 49; 351: 82; 353:87; 605: 83; 664: 79.

${ }^{91}$ El número total de entradas de esta primera parte se ha extraído ponderando la media de entradas por página tras un muestreo representativo de 12 páginas aleatorias del diccionario. El cómputo de las entradas ha sido (señalamos en primer lugar el número de la página y en segundo lugar el número de entradas de la página): 2: 73; 3: 84; 4: 78; 9: 76; $11: 85 ; 84: 78 ; 85: 59 ; 380: 67 ; 383: 77 ; 555: 61 ; 558: 50 ; 559: 50$.
} 
Los artículos lexicográficos en su composición y redacción son también sistemáticos y en el apartado microestructural se atiende estrictamente a la consideración lingüística de la entrada, en principio mediante su caracterización gramatical de la entrada con el uso de las abreviaturas ya comentadas para ofrecer, a continuación, la información relevante en la lengua de salida. La forma de mostrar la información léxica sigue los mismos parámetros ya observados en obras anteriores, pero en esta ocasión se constata una mayor sistematicidad en la cantidad y en la calidad de esa información que proporciona. Se encuentran simples equivalencias (ABREVERATOIO, s. m. Abrevadero, pág. 3, 1) ${ }^{92}$; $\boldsymbol{A B} \boldsymbol{A D D}$. s. m. Abate, pág. 1, II); o bien definiciones perifrásticas cuando no existe una equivalencia exacta (ABBIADARE, v. a. Dar à comer avena, pág. 3, I; ABADEJO. s. m. Specie di merluzzo, pág. 1, II). Pero cuando la entrada exige una mayor extensión, las diferentes acepciones se ordenan correctamente, con regularidad en todos los artículos, incluyendo en cada apartado oportuno la fraseología necesaria. Ejemplos de ello serían:

ACCHITO. s. m. La primera jugada al billar, ó el juego para ver quie es mano. - Di primo acchito. mod. fam. Luego, en seguida. (Pág. 9, I)

ABARCAR. v. a. Abbracciare, premere, contenere, comprendere. - Assumere, Intraprendere. - Addossarsi, incaricarse d'un affare. - Circondare. - Quien mucho abarca, poco aprieta. Prov. Chi tròppo vuole nulla stringe. (Pág. 2, II)

BANDERA. s. f. Bandiera, insegna, stendardo, vessillo. - Drapello, numero di soldati che segue una insegna. - Bandera de paz. Badiera blanca che s'innalbera quando si vuole capitolare. - A banderas desplegadas. Mod. avv. Fig. A viso aperto. - Batir banderas. fr. Far il saluto alla bandiera. - Arriar bandera. - Militar debajo de la bandera de alguno. fr. Seguir il partito di alcuno. - Rendir la bandera. fr. Saluto della bandera. - Salir con banderas desplegadas. fr. Uscire con tutti gli onori. (Pág. 87, II)

Con estos ejemplos en los que se observa una práctica lexicográfica sistematizada, junto al gran número de entradas que incluye, el diccionario de Linati y Delgado puede ser considerado como la culminación de toda una trayectoria de la lexicografía bilingüe español-italiano (Martínez Egido 2009) que no parecía encontrar el cauce adecuado para constituirse con excelencia. El siglo termina con esta gran obra que eleva la relación entre el español y el italiano al mismo nivel que años atrás habían conseguido otras lenguas europeas. Su éxito editorial, a pesar de su calidad ya comentada, fue algo escaso ya que solo tuvo otra reedición en $1897^{93}$, hecho que corrobora el interés que despertó pero, bien es cierto, que el siglo XX traerá otros diccionarios bilingües español-italiano que lo superaran ampliamente en éxito y ventas y que anularán por tanto su vida editorial.

Glosadas las obras lexicográficas más importantes en esta centuria decimonónica correspondientes a los diccionarios de bolsillo y a los diccionarios extensos, la producción lexicográfica bilingüe entre el español y el italiano se completaría con las obras destinadas a la recopilación y explicación de una determinada lengua de especialidad, es decir, con los

\footnotetext{
${ }^{92}$ El número de página se corresponde con la edición que se ha consignado y que se ha utilizado, por lo que todos los ejemplos remitirán a ella. Por realizar el análisis conjunto de ambas partes, detrás del número de página se ofrecerá también el volumen al que pertenece.

${ }^{93}$ Milán, U. Hoepli. Se encuentra reseñada en el Cliro de la Universitá de Bologna.
} 
diccionarios de especialidad. Este sería el caso del Diccionario marítimo de O'Scalan publicado en $1831^{94}$, un diccionario monolingüe de español marítimo que se completa con tres vocabularios bilingües. En su portada se puede leer:

Diccionario / maritimo español / que además de las definiciones de las voces con sus equivalentes en francés, inglés e italiano, contiene tres vocabularios de estos idiomas con las correspondencias castellanas. Redactado / Por orden del Rey nuestro señor. / Autor: / Timoteo O-Scalan. / En orden superior / Madrid en la Imprenta Real / Año de 1831.

Comienza con un prólogo de 48 páginas numeradas con caracteres romanos. Aquí explica sus intenciones, sus fuentes, la forma de consultar el diccionario, así como la descripción del modo de construir los artículos. Apunta el autor que siempre sigue las directrices marcadas por la Academia Española. Entre toda la información que expone, debe destacarse la justificación de la existencia de este tipo de diccionarios y de qué voces deben contener. Así en las páginas V y VI expone:

Tal es la utilidad de los Diccionarios, aun limitados al lenguaje técnico y peculiar de una profesión como la Marina, que, como hemos visto, tiene tanta afinidad con otras artes y ciencias, y que ademas es muy variable en las costas del Océano y Mediterraneo, y aun en sus particulares provincias y distritos. Esto mismo aumenta la dificultad para la formación de un Diccionario náutico, porque si los de las lenguas muertas pueden apurar todo el caudal de sus voces y frases, no hay facilidad respecto á las lenguas vivas, en las cuales el uso vário y caprichoso, los nuevos progresos ó descubrimientos en otras profesiones análogas, y el imperio é influjo de naciones mas poderosas é ilustradas, dilatan ó renuevan el lenguage para expresar los artefactos, las máquinas é invenciones que cada dia proporciona el ingenio fecundo de los hombres, con el fin de simplificar ó aliviar la rudeza de sus trabajos y labores, y de aumentar las comodidades de la vida. Asi es que á semejanza de las horas de los árboles, segun la discreta comparación de Horacio, caen y se envejecen unas voces para dejar lugar á otras recientes y peregrinas: todas, empero, deben darse á conocer en un Diccionario, porque si las del lenguage corriente han de estudiarse para usarlas con propiedad y exactitud, las anticuadas y envejecidas no deben ignorarse si se desea entender la doctrina de nuestros antiguos maestros, ó apreciar las relaciones de nuestros intrépidos navegantes y primitivos descubridores.

Al prólogo le siguen dos páginas de abreviaturas para comenzar el diccionario que abarca 584 páginas. Los artículos del diccionario son de extensión variada, pues lo mismo ofrece una definición concreta de dos o tres líneas que de más de veinte. Al final le añade tres vocabularios marítimos bilingües, el primero francés-español (págs. 1-62), el segundo, inglés-español (págs. 63-127) y, por último, un vocabulario marítimo italiano-español (págs. 129-161). La obra se cierra con 26 páginas de fe de erratas así como de una serie de adiciones a la parte del Diccionario marítimo español.

El vocabulario marítimo italiano-español contiene la información distribuida en dos columnas y en sus 32 páginas contiene 2800 entradas $^{95}$. No presenta lematización, pues

\footnotetext{
${ }^{94}$ Felix San Vicente, en el Cliro de la Universitá de Bologna, reseña otro diccionario bilingüe español-italiano de especialidad: G. Moreali (1841). Diccionario de música italiano-español, La Habana, Imprenta del Gobierno.

${ }^{95}$ El número total de entradas de este vocabulario bilingüe se ha extraído ponderando la media de entradas por página tras un muestreo representativo de 10 páginas aleatorias del diccionario. El cómputo de las entradas ha sido
} 
aparecen como entradas diferentes las diversas acepciones o unidades pluriverbales que plasma, como por ejemplo la palabra Aqua que se desarrolla mediante cinco entradas (acqua, acqua bassa, acqua dolce, Acqua y Acqua planna, pág. 129) ${ }^{96}$. Por ello, en la consideración del número de entradas que posee debe tenerse en cuenta este hecho pues, sería necesario realizar una lematización para saber realmente cuántas entradas lo componen. Tampoco hay unanimidad en la tipología de ellas, porque son tanto unidades univerbales como pluriverbales (Asta di poppa, pág. 131; Asta di prua, pág. 131; Merlino sottile per relingare, pág. 148; Tagliare la gomena, pág. 158). Por todo ello, la construcción de la macroestructura todavía queda anclada en una práctica lexicográfica no acorde con la modernidad que ya se conocía y más, cuando, según el autor, toma como fuente directa el diccionario de la Academia española.

La redacción de la microestructura es muy simple ya que se limita a dar la traducción directa mediante la equivalencia, (Tabernacolo. Bitacora, pág. 158); o mediante una definición perifrástica (Strascinare. Llevar á la rastra ó por la popa, pág. 158). Sólo en los casos en que la entrada tiene varias acepciones en el vocabulario marinero se extiende algo más (Testa. Sombrero del cabestrante.// Culo de vogota. // Serviola. // Tamborete. // Cabeza de un tablón.// Penol. Tiene todos estos significados en sus casos ó según el aditamento que lo califica ó determina, pág. 159). Aunque estos casos son muy excepcionales pues, si se trata de términos marítimos, debe contar la monosemia como rasgo importante en ellos.

En definitiva, este tipo de diccionarios de especialidad continúa con la tradición iniciada en la centuria anterior, cuyo antecedente más directo sería la obra de Terreros y Pando ya reseñada, y que demuestran el interés por las lenguas de especialidad directamente relacionado con los avances culturales y técnicos del momento. Serán el complemento necesario para el desarrollo de la actividad lexicográfica, la cual intenta atender siempre a las demandas del público receptor, de ahí que en esta centuria convivan los diccionarios de bolsillo, los diccionarios extensos y los diccionarios de lenguas de especialidad.

\section{CONCLUSiOnes}

Tras la exposición de este estudio, se ha podido comprobar el origen y el desarrollo de la lexicografía bilingüe española e italiana desde el siglo XVI hasta el siglo XIX. El origen radicaría en la necesidad de aprender lenguas extranjeras, surgida de la realidad europea de los siglos XV y XVI. En ese momento cronológico se produciría un asentamiento de las bases teóricas y prácticas que presidirán toda la técnica lexicográfica posterior con el magisterio indudable de la obra de Antonio de Nebrija. Con él se rompe la tradición de la enseñanza medieval de lenguas $\mathrm{y}$, como instrumento para ello, se crearon diversos materiales, entre los que hay que incluir los nuevos diccionarios bilingües.

(señalamos en primer lugar el número de la página y en segundo lugar el número de entradas de la página): 129: 66; 131: 92; 134: 94; 139: 94; 143: 96; 148: 92; 149: 75; 153: 104; 158: 91; 161: 79.

${ }^{96}$ El número de página se corresponde con la edición que se ha consignado y que se ha utilizado, por lo que todos los ejemplos remitirán a ella. 
El siglo XVI supuso el desarrollo de la lexicografía bilingüe del español con el resto de las lenguas de la Europa occidental con dos tipos de producciones lexicográficas que se perpetuarán durante todo el periodo estudiado: las obras de corta extensión, como las nomenclaturas y los pequeños vocabularios; y los diccionarios extensos, caracterizados por el no poner limitaciones en el número de voces que recogían. En este último grupo se incluye la obra de Las Casas que inaugura la tradición en la producción lexicográfica bilingüe española-italiana y que se verá superada a principios del siglo XVII con el vocabulario de Franciosini, con el que se consolida esta trayectoria bilingüe.

El siglo XVIII no es muy significativo en la evolución de la lexicografía bilingüe española-italiana, pues no hay aportaciones que superen lo ya realizado en las centurias anteriores. Junto a las reediciones del diccionario de Lorenzo Franciosini, sólo se constata la obra de Terreros como testimonio de esta práctica lexicográfica y de la importancia de las voces de especialidad. Sin embargo, el siglo XIX es todo lo contrario, y se asiste a un resurgir de los diccionarios, tanto extensos como portátiles e, incluso, de lenguas de especialidad, en consonancia con la demanda sociocultural existente.

Se podría deducir de esta evolución que los diccionarios surgen de la necesidad de los usuarios y que son, en realidad, un bien de consumo por encima de lo que puede significar la práctica lexicográfica como actividad de enriquecimiento lingüístico para una sociedad determinada, de ahí que en cada una de las épocas estudiadas haya habido un desarrollo distinto y, como consecuencia, unos productos diferentes.

En lo referente a la construcción de los diccionarios también se ha logrado una evolución positiva. Las macroestructuras se han ido desarrollando atendiendo siempre a criterios prácticos, como es la necesidad de un vocabulario concreto y, poco a poco, contemplando criterios lingüísticos, tales como la lematización. En este sentido el mejor diccionario sería el último analizado en el siglo XIX, el de Linati-Delgado, con 41.600 entradas en su primera parte, italiano-español, y con 47.300 en su segunda, españolitaliano, ya que supera a los publicados en esa centuria y deja muy atrás las voces incluidas por Las Casas y Franciosini, además de que estas obras no presentaban las voces lematizadas.

Las microestructuras también presentan una evolución positiva. De ofrecer prácticamente solo la equivalencia, siguiendo a Nebrija, por parte de Las Casas, a procurar una información muy práctica como en el caso de Franciosini y a superar el caos que reinaba en su obra para llegar a una sistemática clara en Linati-Delgado, hasta el punto de que la redacción del artículo lexicográfico que muestra este último autor en su diccionario es perfectamente asumible al ser comparada con la que ofrecen otros grandes diccionarios del siglo XX.

Por todo ello, puede concluirse que la práctica lexicográfica bilingüe español-italiano tuvo una evolución positiva a lo largo de todo el periodo estudiado. Siempre estuvo presente en el desarrollo de la lexicografía bilingüe del español, siendo por ello uno de los puntales básicos del progreso de esta disciplina y, sobre todo, de sus productos, los diccionarios. Ha sido también un exponente de las relaciones habidas entre las dos lenguas a lo largo de la historia y ha quedado como testimonio del quehacer lexicográfico del español, por lo que no puede obviarse en cualquier estudio histórico del léxico español. 


\section{REFERENCIAS BIBLIOGRÁFICAS}

\section{Fuentes}

ACCADEMici Della CRUSCA (1612). Vocabulario degli Accademici della Crvsca, con tre indici delle voci, locuzioni, e prouerbi latini, e greci, posti per entro l'opera, Venecia, G. Alberti.

AlCALÁ, P. de (1505). Vocabulista arabigo en letra castellana, Granada.

Alumno, F. (1543). Le richezze della lingua volgare, Venecia.

ANÓNIMO (1551). Vocabulario de quatro lenguas. Tudesco, francés, latino y español, muy provechoso para los que quisieren aprender estas lenguas, Lovaina.

ANÓNIMO (1854). Nuevo Diccionario español-italiano, italiano-español, París, Rosa y Bouret.

AnÓNIMO (1854). Nuevo Diccionario italiano-español y viceversa, Gerona, Imprenta de Grases.

ANÓNIMO (1873). Nuevo Diccionario italiano-español y español-italiano, Milán, Ferrario.

BERLAIMONT, N. (1530). Vocabulaire poru apprendre légérament à bien lire, escripre, parle François et Flameng, lequel est mis tout le plus part personnaiges, Amberes.

Boselli, C. (1893). Nuovo Dizionario spagnolo-italiano e italiano-spagnolo, Milán, Fratelli Trevers, 2 vol.

CACCiA, J. (1869). Nuevo Diccionario italiano-español, París, Garnier Hermanos.

CANINI, M. A. (1875). Diccionario español-italiano-español, Milán / Nápoles.

CAlepino, A. (1558). Dictionarium Quator Linguarum, Gallicae, Latinae, Italicae, Hispanicae, Lovaina, B. de Gravio.

CAstro, A. de (1852). Gran Diccionario de la Lengua castellana, Madrid, Seminario Pintoresco Español y de la Ilustración.

CoRmon, J. L. B., V. MANNI (1805). Dizionario da tasca italiano-spagnuolo e spagnuoloitaliano, Lyon, Cormon y Manni.

Covarrubias Orozco, S. (1611). Tesoro de la lengua castellana o española, Madrid. Ed. por L. Sánchez y M. Riquer, Barcelona, S. A. Horta, 1953.

Covarrubias Orozco, S. (1611): Tesoro de la lengua castellana o española, Madrid. Ed. por L. Sánchez, F. Maldonado y M. Camarero, Madrid, Castalia, 1994.

DomíngueZ, J. R. (1846-1847). Diccionario Nacional o Gran Diccionario Clásico de la Lengua Española, Madrid, Bernat.

GAtTEl, C. M. (1790). Nouveau dictionnaire françois-espagnol et espagnol-françois, Lyon, Bruyset Freres.

GonzÁlez Arnao, V. (1822). Diccionario de la lengua castellana, Madrid, P. Sanz y Sanz. 
GonzÁlez DE MendozA, N. (1761): Diccionario general de las dos lenguas española y francesa, Madrid, A. Ortega.

Herrero y RuBiRA, A. M. (1744). Diccionario universal, francés y español, Madrid, Imprenta del Reyno.

HoRnkens, H. (1599). Recueil de Dictionnaires François, Espaignolo et Latino. Recopilación de Diccionarios Franceses, Españoles y Latinos. Congesta Dictionariorum, Gallicorum, Hispanicorum et Latinorum, Bruselas, R. Velpius.

JUNIUS, A. (1567). Nomenclator omnium rerum propria nomia variis linguis explicata indicans, Amberes.

LAS CASAS, B. de (1570). Vocabulario de las dos lenguas toscana y castellana, Sevilla, F. de Aguilar.

LANDUCCI, N. (1562). Dictionarium Lingue Toscane/ A Nicholao Landuchio ciuita/ tis Luce regionis Tofcane fue/vernacule lingua peritiffimo/Vocabulario Español, Italiano/ Frances y Vyzcaino. Anno. I.D.LXII. Manuscrito 8431 de la Biblioteca Nacional, Madrid.

LEDEL, J. (1565). Vocabulario de los vocablos que mas comunmente se suelen usar, Alcalá.

LinAti-Delgado, F. (1887). Nuovo Dizionario spagnuolo-italiano, Barcelona, successori di N. Ramirez e Compagni.

MARTínez DEL Romero, A. (1844). Dizionario italiano-spagnuolo e spagnuolo-italiano, Tomo Primo, italiano-sapagnuolo, Madrid, Son I. Boix.

Masson, J. R. (1826). Diccionario de la lengua castellana, por la Academia Española, París, Masson e hijo.

MinsheU, J. (1599). A dictionarie in spanish and english, Londres. Ed. por G. Guerrero y F. Pérez, Málaga, Publicaciones de la Universidad de Málaga, 2000.

Moreali, G. (1841). Diccionario de música italiano-español, La Habana, Imprenta del Gobierno.

NebriJA, Antonio de (1492). Lexicon hoc est Dictionarium es Sermone Latino in Hispaniensem, Salamanca, Ed. Facsímil y estudio preliminar de Colón, G. y Soberanas A. (1979), Barcelona, Puvill-Editor.

NeBriJA, A. de (1495). Dictionarium es hispaniensi in latinum sermonen o Vocabulario español-latín, Salamanca. Ed. facsímil de la RAE, 1951; segunda ed. patrocinada por la Asociación de Amigos de la RAE, Madrid, 1989.

NúÑEZ DE TABoAdA, M. (1822). Diccionario castellano, París, Seguin.

O’Scalan, T. (1831). Diccionario marítimo español, Madrid, Imprenta Real.

Oudin, C. (1607). Tesoro de las lenguas francesa y española, París, M. Orry.

PAlet, J. (1604). Diccionario muy copioso de la lengua española y francesa, París, M. Guillemet.

Peñalver, J. (1842). Panléxico. Diccionario Universal de la Lengua española, Madrid, I. Arboix. 
PerCyVAlL, R. (1591) Bibliotheca Hispanica, containig a grammar, with a dictionarie in Spanisch, English and Latine, gathered out of divers good authors: very profitable for the studious or the Spanish toong, by R. Percyvall, Gent., the dictionarie being enlarged with the latine by the advice and conference of Master Thomas Doyley, Doctor in Phisicke, Londres.

Pla y TORRES, C. (1826). Diccionario de la Lengua castellana por la Academia española, París, Cormon y Blanc.

Rosal, F. de (1601). Diccionario etimológico. Ed. por E. Gómez Aguado, Madrid, C.S.I.C., 1992.

Rosterre, E. (1771). Reglas a cerca de la lengua Toscana, o Italiana, Forli, A. Marozzi.

SAlvÁ, V. (1846). Nuevo Diccionario de la lengua castellana, París, Fournier.

SEJOURnAnt, N. de (1749). Nouveau Dictionnaire espagnol-français et latin, París, Ch. A. Jombert.

Sobrino, F. (1705). Diccionario nuevo de las lenguas española y francesa, Bruselas, F. Foppens.

SocietÀ Di Professori (1868). Dizionario italiano-spagnolo, spagnolo-italiano, Milán, P. Carrara.

SOCIEDAD Literaria (1853). Nuevo diccionario de la Lengua castellana, París, Tosa y Bouret.

TERREROS Y PANDO, E. de (1786-1793). Diccionario castellano con las vocex de ciencias y artes, Madrid, Viuda de Ibarra, 4 vols. Ed. facsímil con prólogo de M. Alvar Ezquerra, Madrid, Arco-Libros, 1987.

TORRE OCÓN, F. de la (1728-1731). El maestro de las dos lenguas. Diccionario español y francés; francés y español, Madrid.

VitTORI, G. (1609). Tesoro de las tres lenguas francesa, española e italiana, Ginebra, Ph. Albert \& A. Pernet.

VV. AA. (1853-1855). Diccionario enciclopédico de la Lengua Española, Madrid, Gaspar y Roig.

\section{Estudios críticos}

ACERo DurÁNTEZ, I. (1991). "Incorporaciones léxicas en el Vocabulario de las dos lenguas toscana y castellana de Cristóbal de las Casas". Anuario de Estudios Filológicos 14, 7-14.

ACERo DurÁNTEZ, I. (2003). "La Lexicografía plurilingüe del español”. Lexicografía española, A. M. Medina Guerra (ed.), Madrid, Ariel, 175-204.

Alemany, R. (1981). "Un antecedente olvidado de Antonio de Nebrija: la obra lexicográfica de Alonso de Palencia”. Item. Revista de Ciencias Humanas 5, 119-132.

Alvar EzQuerra, M. (1992). "Nebrija, autor de diccionarios". Cuadernos de Historia moderna 13, 267-285. 
Alvar EzQuerra, M. (1994). "Sapanish lexicographie". Lexicon der Romanische Linguistik, t. V/1, 636-651.

Alvar EzQuerra, M. (1995). "Los diccionarios del español en su historia”. International Journal of Lexicography 8/3, 173-201.

Alvar EzQUERRA, M. (1998). “Nebrija ¿comprendido?”. Estudios de Lingüística y Filología española. Homenaje a Germán Colón, Madrid, Gredos, 29-37.

Alvar EzQUERRA, M. (2002). "El Vocabulario italiano e spagnolo de Lorenzo Franciosini". Alvar Ezquerra, De antiguos y nuevos diccionarios del español, Madrid, Arco-Libros, 191-220.

Álvarez De MirandA, P. (1992). "En torno al Diccionario de Terreros". Bulletin Hispanique 94/2, 559-572.

Ayala CAstro, M. C. (1992). "El concepto de nomenclatura". Euralex '90 Proceedings. Actas del IV Congreso Internacional, Barcelona, Biblograf, 437-444.

AZORÍN FERNÁNDEZ, D. (2000). Los diccionarios del español en su perspectiva histórica, Alicante, Publicaciones Universidad de Alicante.

AZORÍN FERNÁNDEZ, D. (2003). "La lexicografía como disciplina lingüística”. Lexicografía española, A. M. Medina Guerra (ed.), Madrid, Ariel, 31-52.

AZORÍN FERnÁNDEZ, D. (2003b). "Neologismos incorporados por Salvá en el Nuevo Diccionario de la Lengua Castellana". ELUA 17, 107-139.

AzORÍn FERnÁNDEZ, D. (2004). "La dimensión diacrónica en el Nuevo Diccionario de la Lengua Castellana (1846) de Vicente Salvá". Archivo de Filología Aragonesa 59-60, 197-210.

AZORÍn FERNÁNDEZ, D. (2006). “El legado de Covarrubias”. Insula Enero-Febrero, 4-7.

AZORÍN FERNÁNDEZ, D. (2007). "Salvá y la Academia Española: ¿Dos maneras de concebir el diccionario de la lengua?”. Abhandlungen zur Sprache und Literature 168, 17-32.

Azorín Fernández, D., M. I. SANTAMARÍA PÉREZ (2004). "El Diccionario de Autoridades (1726-1739) y el Diccionario Castellano (1786-1793) de Terreros y Pando ante la recepción de las voces de especialidad”. Revista de Investigación Lingüística 7, 49-69.

Bourland, C. B. (1933). "The Spanish Schoolmaster and the polyglot derivatives of Noel Berlainont's Vocabulary”. Hispanic Revue 81, 283-318.

Bueno Morales, A. M. (1996). "La lexicografía no académica del siglo XIX: el Diccionario Enciclopédico de la lengua española, publicado por la editorial Gaspar y Roig”. Estudios de historia de la lexicografia del español, M. Alvar Ezquerra (coord.), Málaga, Universidad de Málaga, 151-157.

CARAvolas, J.-A. (1995). “Apprendre à parler une langue étrangère à la Renaissance". Historiographia Linguistica 22, 275-309.

CARriazo Ruiz, J. R., M. J. MANChO DuQue (2003). "Los comienzos de la lexicografía monolingüe". Lexicografía española, A. M. Medina Guerra (ed.), Madrid, Ariel, 205234.

CARriscondo, F. M., N. M. Contreras IZquierdo, I. SÁnChez LóPez, M. I. SANCho RODRíGUEZ (1999). "La lexicografía bilingüe del español y las lenguas románicas". 
Cinco siglos de Lexicografía del español, I. Ahumada Lara (ed.), Jaén, Universidad de Jáen, 269-306.

CAZORLA VIVAS, M. C. (2005). Lexicografía bilingüe con el español y el francés de los siglos XVIII y XIX. Tesis Doctoral, 2002, CC-ROM, Madrid, Servicio de Publicaciones, http://www.ucm.es/BUCM/tesis/fll/ucm-t26053.pdf

COOPER, L. (1960). “Girolamo Vittori y César Oudin: un caso de plagio mutuo”. NRFH 14, $3-20$.

COOPER, L. (1962). "El Recueil de Hornkens y los diccionarios de Palet y Oudin", NRFH $16,297-328$.

CORPAS, G. (1997). Manual de Fraseología española, Madrid, Gredos.

GallinA, A. M. (1959). Contributti alla storia della lessicografia italo.espagnola dei secoli XVI e XVII, Firenze, L. S. Olschiki.

GAllinA, A. M. (1991). "La lexicographie bilingue espagnol-italien, italien-espagnol". Wöterbücher. Dictionaries. Dictionnaires. Ein internationales Handbuch zur Lexikographie. An internatioanl encyclopedia of lexiocography. Encyclopédie internationale de lexicographie, F. J. Hausmann y otros (eds.), Berlín / Nueva York, W. de Gruyter, 2991-2997.

GArcía Platero, J. M. (2003). "La lexicografía no académica en los siglos XVIII y XIX". Lexicografia española, A. M. Medina Guerra (ed.), Madrid, Ariel, 263-280.

Gómez AguAdo, E. (1992). Francisco del Rosal (¿1537-1613?), lexicógrafo y humanista, Madrid, CSIC.

GONZÁlEZ REY, M. I. (1998). "Estudio de la idiomaticidad en las expresiones fraseológicas". Estudios de fraseología y fraseografía del español actual, G. Wotjak (ed.), Madrid, Iberoamericana; Frankfurt am Main, Vervuert.

Guerrero Ramos, G. (1992). “La lexicografía bilingüe desde Nebrija a Oudin”. Euralex '90 Proceedings. Actas del IV Congreso Internacional Benalmádena (Málaga), Barcelona, Biblograf, 463-471.

Guerrero Ramos, G. (1995). El léxico en el 'Diccionario' 1492 y en el 'Vocabulario' (¿1495?) de Nebrija, Sevilla, Universidad de Sevilla, Ayuntamiento de Lebrija.

LÉPINETTE, B. (1989). "Contribution à l'étude du Tesoro de la Lengua Española o Castellana (1611) de Sebastián de Covarrubias”. Historiographia Linguistica 16/3, 257 310.

LOPE BlANCH, J. M. (1990). "El vocabulario de las dos lenguas toscana y castellana de Cristóbal de Las Casas". Lope Blanch, Estudios de historia lingüística hispánica, Madrid, Arco-Libros, 111-124.

Martín Gamero, S. (1961). La enseñanza del inglés en España (Desde la Edad Media hasta el s. XIX), Madrid, Gredos.

MARTínez EgIDO, J. J. (2002a). La obra lexicográfica de Lorenzo Franciosini: Vocabulario italiano-español, español-italiano (1620), Alicante, Fundación Biblioteca Virtual Miguel de Cervantes, Universidad de Alicante, http://www.cervantesvirtual.com/FichaObra.html?Ref=7570 
Martínez EgIdo, J. J. (2002b). "El Tesoro de Oudin (1607) y el Vocabulario de Franciosini (1620): dos diccionarios bilingües del español”. Con Alonso Zamora Vicente, J. C. Rovira (ed.), Alicante, Universidad de Alicante, t. II, 815-823.

MARTínez EGIDO, J. J. (2003). "La utilización de fuentes en la realización de diccionarios: ¿Covarrubias (1611), fuente directa en la microestructura de Franciosini (1620)?”. ELUA 21, 413-426.

MARTínez EgIDO, J. J. (2004). "El Vocabulario (1620) de Lorenzo Franciosini: realización de su macroestructura". De Lexicografia: Actes del I Symposium Internacional de Lexicografia, P. Battaner y J. DeCesaris (eds.), Barcelona, Institut Universitari de Lingüística Aplicada, 571-579.

MARTínez EGIDO, J. J. (2006a). "La enseñanza-aprendizaje del español para extranjeros: Lorenzo Franciosini, un maestro de lenguas del siglo XVII". Análisis del discurso: Lengua, Cultura, Valores, Madrid, Arco Libros, t. I., 1099-1113.

Martínez Egido, J. J. (2006b). La lexicografía medieval. Alfonso Fernández de Palencia. Antonio de Nebrija. Rodrigo Fernández de Santaella. E-Excellence, www.liceus.com

MARTíneZ EgIDO, J. J. (2007). La lexicografía bilingüe y plurilingüe de los siglos XVI y $X V I I$. E-Excellence, www.liceus.com

MARTíNEZ EGIDO, J. J. (2008a). "La ironía: herramienta en la enseñanza del español como lengua extranjera (Los diálogos del siglo XVII)". ELUA 22, 229-243.

MARTínEZ EGIDO, J. J. (2008b). "La Lexicografía hispano-italiana: tras las huellas del Vocabulario de Lorenzo Franciosini, de 1620 a 1187". La lexicografía bilingüe y didáctica: ayer y hoy (=Anexos Revista de Lexicografia 8), M. Campos Souto y E. M. González González (eds.), La Coruña, Universidade da Coruña, 93-102.

MARtínez EgIDo, J. J. (2009). "Descripción analítica del Nuevo Diccionario italianoespañol, español-italiano". Mediazioni 6, 1-20. http://www.mediazioni.sitlec.unibo.it/index.php/no6-anno2009.html

Martínez Egido, J. J., L. Ruiz GuRiLlo (2004). "Las unidades fraseológicas en el inicio de la Lexicografía del español (1495-1620)". Actas del VI Congreso Internacional de Historia de la Lengua Española, Madrid, Arco-Libros, 1531-1543.

Medina Guerra, A. M. (1991). "Modernidad del Universal Vocabulario de Alfonso Fernández de Palencia". ELUA 7, 45-60.

NiEDEREHE, H.-J. (2005). Bibliografía cronológica de la Lingüística, la Gramática y la Lexicografía del español (Bicres), desde el año 1700 hasta el año 1800, Amsterdam / Filadelfia, J. Benjamins.

NieTo JiMÉNEZ, L. (1992). "Coincidencias y divergencias entre los diccionarios de Nebrija, Las Casas y Percyvall". Actas del Congreso Internacional de Historiografia Lingüística. Nebrija V Centenario, Murcia, Servicio de Publicaciones de la Universidad de Murcia, t. III, 351-365.

NiETO JiMÉNEZ, L. (2000). "Repertorios lexicográficos españoles menores en el siglo XVI". Cinco siglos de Lexicografía Hispánica. IV Seminario de Lexicografía Hispánica, I. Ahumada Lara (ed.), Jaén, Universidad de Jaén, 203-223. 
Perona, J. (1994). “Antonio de Nebrija, Lexicógrafo". Actas del Congreso Internacional de Historiografia Lingüistica. Nebrija $V$ Centenario, R. Escavy Zamora, J. M. Hernández Terrés y A. Roldán Pérez (eds.), Murcia, Servicio de Publicaciones de la Universidad de Murcia, 449-476.

Ruhstaller, S. (2003). "Las obras lexicográficas de la Academia". Lexicografía española, A. M. Medina Guerra (ed.), Madrid, Ariel, 235-262.

Ruiz Gurillo, L., J. J. MARTíNEZ EgIDO (2004). "La integración de la fraseología en los primeros diccionarios del español: el Vocabulario (1620) de Lorenzo Franciosini". Nuevas aportaciones a la Historiografía Lingüistica. Actas del IV Congreso Internacional de la SEHL, C. Corrales Zumbado y otros (eds.), Madrid, Arco-Libros, t. II, 1055-1066.

San Vicente, F. (2007). El Diccionario castellano de E. de Terreros y la lexicografía plurilingüe. Conferencia Plenaria en el Congreso Conmemorativo del III Centenario del nacimiento de Terreros: Esteban de Terreros y Pando: vizcaíno, polígrafo y jesuita ante los retos del s. XVIII, celebrado en Bilbao del 21 al 23 de noviembre de 2007.

SAN ViCENTE, F. (2008). Subject index of bilingual lexicography Italian-Spanish and Spanish-Italian dictionaries. Cliro, Centro Linguistico Bolonia, Università di Bologna, http://hesperia.cliro.unibo.it/ricerca_en/index.asp

SÁNCHEZ PÉREZ, A. (1992). Historia de la enseñanza del español como lengua extranjera, Madrid, SGEL.

SECO, M. (1987). "El nacimiento de la lexicografía española no académica”. Estudios de Lexicografía española, Madrid, Paraninfo, 97-110.

Von Gemmingen, B. F. (2003). "Los inicios de la lexicografía española". Lexicografía española, A. M. Medina Guerra (ed.), Madrid, Ariel, 151-174.

José Joaquín Martínez Egido

jj.martinez@ua.es

Dpto. de Filología Española, Lingüística General y

Teoría de la Literatura

Facultad de Filosofía y Letras

Carretera San Vicente del Raspeig s/n

03690 San Vicente del Raspeig - Alicante 